\title{
Perceived preparedness of graduate assistant novice approved clinical instructors for supervision of undergraduate athletic training students
}

Christopher M. Pircher

West Virginia University

Follow this and additional works at: https://researchrepository.wvu.edu/etd

\section{Recommended Citation}

Pircher, Christopher M., "Perceived preparedness of graduate assistant novice approved clinical instructors for supervision of undergraduate athletic training students" (2008). Graduate Theses, Dissertations, and Problem Reports. 4415.

https://researchrepository.wvu.edu/etd/4415

This Thesis is protected by copyright and/or related rights. It has been brought to you by the The Research Repository @ WVU with permission from the rights-holder(s). You are free to use this Thesis in any way that is permitted by the copyright and related rights legislation that applies to your use. For other uses you must obtain permission from the rights-holder(s) directly, unless additional rights are indicated by a Creative Commons license in the record and/ or on the work itself. This Thesis has been accepted for inclusion in WVU Graduate Theses, Dissertations, and Problem Reports collection by an authorized administrator of The Research Repository @ WVU. For more information, please contact researchrepository@mail.wvu.edu. 
Perceived Preparedness of Graduate Assistant Novice Approved Clinical Instructors for Supervision of Undergraduate Athletic Training Students

Christopher M. Pircher, ATC

Thesis submitted to the

School of Physical Education

at West Virginia University in

partial fulfillment of the requirements

for the degree of

Master of Science

In

Athletic Training

Michelle A. Sandrey, PhD, ATC, Chair

Mia Erickson, EdD, PT, CHT, ATC

Amy Hile, MA, ATC

School of Physical Education

Morgantown, WV

2008

Key words: clinical education, approved clinical instructor preparedness, approved clinical instructor training 


\begin{abstract}
Perceived Preparedness of Graduate Assistant Approved Clinical Instructors for Supervision of Undergraduate Athletic Training Students
\end{abstract}

\title{
Christopher M. Pircher, ATC
}

Context: Athletic training clinical education has gone through reform since the Commission on Accreditation of Athletic Training Education (CAATE) has become the accrediting body of the profession. The amount of time that an undergraduate athletic training student has in the clinical education setting is very valuable to their development as a certified athletic trainer (ATC) and possibly as an approved clinical instructor (ACI). Therefore, the preparedness of the approved clinical instructor is very crucial. Objective: The purpose of the study is to determine the perceived preparedness of graduate assistant novice ACIs in the supervision of undergraduate ATSs in clinical education. Design: The design of the study was a prospective descriptive analysis, through use of a questionnaire to determine the preparedness of graduate assistant novice approved clinical instructors at twenty-seven CAATE accredited undergraduate athletic training programs that have been accredited for five or more years. Setting: Twenty- seven CAATE programs that have been accredited for five or more years. Participants: This study included thirty-three novice approved clinical instructors. This was a sample of convenience based on the twenty-seven CAATE institutions that agreed to participate in the study. Participants included in this study were graduate assistant ACIs at an institution that has a CAATE accredited undergraduate athletic training education program for five years or more and be a graduate assistant ATC that has one year of clinical experience and attended a ACI training workshop at their institution. The participant must also have the responsibility of supervising and evaluating ATSs. The participants that will be excluded are those institutions who do not have graduate assistant ATCs supervising undergraduate ATSs, a CAATE undergraduate accredited athletic training education program (ATEP) for under five years, and if the position is a one year internship. Participants were excluded if the ACIs at the above mentioned institutions are not considered to be a novice graduate assistant ACIs according to the definition of the study. Intervention: The undergraduate program director received an email asking if their institution was willing to participate in the study. Once confirmation of willingness to participate was received, then an initial cover letter with the link to the questionnaire was e-mailed to the program director to forward to the participants to complete. After a two week period, a second cover letter that included the link to the questionnaire was e-mailed encouraging participants to complete the questionnaire if they had not already done so. Main Outcome Measures: Based on the responses the graduate assistant novice ACIs will feel that they were prepared to supervise athletic training students in the clinical setting. Based on the responses the graduate assistant novice ACIs will feel that the ACI training workshop prepared them in their first year as an ACI. Results: Of the 178 initial e-mails sent out, 27 institutions agreed to participate. Thirtythree of the possible 140 novice graduate assistant ACIs completed the electronic questionnaire for a return rate of $23.5 \%$. Forty-six percent of ACI graduate student, had 
less than one year of experience as an ACI, $36.4 \%$ were certified athletic trainers for two years, $72.7 \%$ were currently working in the college / university setting, and $45.5 \%$ supervised three to four undergraduate ATSs. Fifty-five percent of the participants were supervised by a graduate assistant ACI during their own undergraduate experience. The majority of all of the participants felt prepared in the areas of learning styles, ACI responsibilities, evaluation and feedback of student performance, and ACI preparation. The participants felt most prepared to evaluate ATS clinical skills $(61 \%, n=20)$ and least prepared to evaluate professional behaviors $(6 \%, \mathrm{n}=2)$. The participants felt most prepared to provide feedback in ATS clinical skills $(67 \%, n=22)$ and least prepared to provided feedback in professional behaviors $(9.1 \%, \mathrm{n}=3)$. When asked to rank the ACIs first year, the mean score reported was $6.97 \pm 1.2$ and the range was 4 to 10 . The greatest challenges the ACI experienced were time constraints $(69.7 \%, n=23)$, controlling the learning environment $(57.6 \%, \mathrm{n}=19)$, and understanding institutional policies and procedures (39.4, $\mathrm{n}=13)$. Conclusion: The participants who responded to the questionnaire, mostly felt prepared to be an ACI in their novice years. Evaluating and providing feedback on professional behaviors may be a weakness among novice ACIs. Most of the participants felt that that ACI training workshop was beneficial but there was about one-quarter of the participants who felt that the training workshop was not beneficial to their development as an ACI. 


\section{ACKNOWLEDGEMENTS}

I would like to take this time and thank my family and my friends who have tolerated me through out this long grueling process. Without the continued support I do not think I would have completed this component of my education / professional career.

I would also like to thank Dr. Michelle A. Sandrey for her guidance throughout this process. I have learned to appreciate individuals like her who enjoy performing research because I have learned that it takes a special person to do so. Dr. Sandrey you were a great help and I am glad you were a part of it all. Thank you for giving me the opportunity to come to WVU and obtaining my masters.

I would like to thank Mia Erickson and Amy Hile for all of their guidance and help with completion of this endeavor. Thank you for being there to listen to my venting about certain aspects of my thesis. And finally thank you for agreeing to be on my committee and taking the time out of your busy schedule / positions as educators to assist me in my thesis.

I would also like to thank John Spiker, Mike Casselman, Jeff Erickson, and the rest of the HealthWorks Rehab and Fitness staff for allowing me the opportunity to continue my professional growth as a certified athletic trainer.

Lastly, I would like to thank Brain Coulombe, Rick Roswell, and Matt Matocha for instilling the professional values and an excellent undergraduate education needed to be successful in graduate school as well as succeed in life as a certified athletic trainer. 


\section{TABLE OF CONTENTS}

ACKNOWLEDGEMENTS........................................ iv

TABLE OF CONTENTS.......................................... $\quad \mathrm{v}$

LIST OF TABLES................................................ vi

LIST OF FIGURES...................................................................... vii

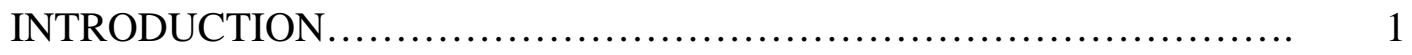

METHODS............................................................ 2

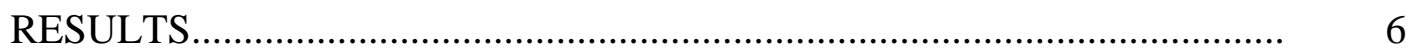

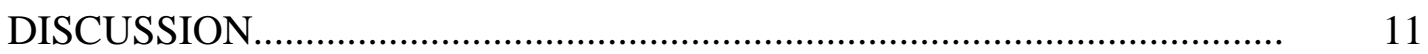

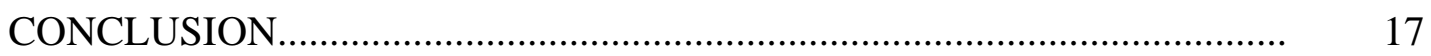

REFERENCES...................................................... 19

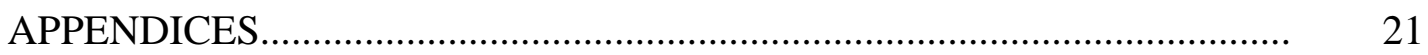

APPENDIX A. THE PROBLEM.................................................. 22

APPENDIX B. LITERATURE REVIEW...................................... 30

APPENDIX C. ADDITIONAL METHODS................................... 51

APPENDIX D. ADDITIONAL RESULTS..................................... 65

APPENDIX E. RECOMMENDATIONS FOR FUTURE RESEARCH 73

ADDITIONAL REFERENCES...................................... 74 


\section{LIST OF TABLES}

Table

Page

B1. Principles of a Graduate Education.................................... 40

B2. Content Area and Description of Content Area for an ACI Training Workshop... 48

C1. Initial Email to Undergraduate Program Directors......................... 51

C2. Initial Cover Letter to Undergraduate Program Director..................... 52

C3. Follow-up Cover Letter to Undergraduate Program Director.................. 53

C4. Questionnaire to Novice Graduate Assistant Approved Clinical Instructors...... 54

D1. Demographic Characteristics of Questionnaire Participants........................... 65

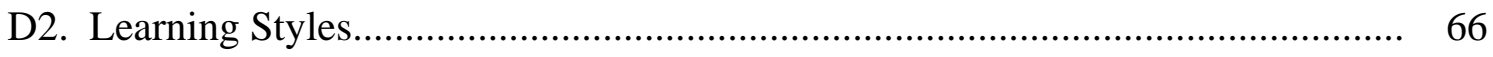

D3. Approved Clinical Instructor Responsibilities........................................ 67

D4. Evaluation and Feedback of Student Performance.................................... 69

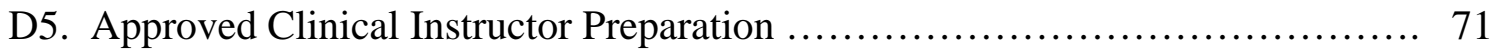




\section{LIST OF FIGURES}

Figure

Figure D1. Approved Clinical Instructor Perceived Greatest Challenges..................... 72 


\section{INTRODUCTION}

Athletic training clinical education can be described as the portion of the athletic training student's (ATS) professional preparation that involves the formal acquisition, practice, and evaluation of clinical proficiencies through classroom, laboratory, and clinical experiences in medical care environments. ${ }^{1}$ Clinical education comprises a large portion of professional preparation in athletic training and other allied health care fields. Entry-level certified athletic trainers perceive that approximately 53\% of their entry-level professional education came from clinical education ${ }^{1}$ as compared to physical therapy where clinical education has been reported to be approximately $23 \%$ to $30 \%$ of the total curriculum. $^{2}$

The approved clinical instructor (ACI) is an individual who is an appropriately credentialed professional, identified and trained by the athletic training programs clinical instructor educator (CIE). The ACI provides instruction and evaluation of the ATS's educational and/ or clinical proficiencies. ${ }^{3}$ To become an ACI, the individual must meet minimal standards set forth by the Commission on Accreditation of Athletic Training Education (CAATE). The requirements to become an ACI include: 1) attending an ACI training workshop at their institution; 2) being a certified athletic trainer (ATC) for a year; and 3) having one year of clinical experience. ${ }^{4}$

New educational standards require ACIs to play a much more significant role in the education of their assigned students than in previous years. Approved clinical instructors must provide daily personal contact and supervision of students and be physically present in order to intervene in the delivery of health care if necessary. ${ }^{5}$ In addition to supervision, they also are responsible for evaluating the ATSs in the 
competencies and proficiencies defined and set forth in the Athletic Training Educational Competencies. ${ }^{4}$ However, many of the current ACIs have been selected because of their professional skills rather than their teaching abilities and do not have formal preparation in education. ${ }^{2,6}$ Athletic training programs accredited by the Commission on Accreditation of Allied Health Education Programs (CAAHEP) (now CAATE) depend on ATCs who have less than one year of experience to provide ATS supervision during clinical education. ${ }^{7}$ Stemmans and Gangstead, ${ }^{7}$ identified that ATCs in their initial clinical instructor experiences tend to lack necessary clinical-instruction knowledge, skills, and abilities to facilitate ATS behaviors in the clinical setting.

As the demand for the supervision and evaluation of ATSs increases, and the profession continues to grow, there is an increasing need for better training and development of clinical instructors. ${ }^{8}$ Yet, many of the current ACIs are novice in teaching as well as the in the profession and consequently have limited experience in the supervision of ATSs. Many ACIs are also newly certified graduate assistants. There is also inadequate published research on the preparation of ACIs, especially those who are graduate assistants. By gathering data from graduate assistant novice ACIs one should be able to ascertain whether the current ACI training is adequate for preparing ACIs. Therefore, the purpose of the study is to determine the perceived preparedness of graduate assistant novice ACIs in the supervision of undergraduate ATSs in clinical education.

\section{METHODS}

The design of this study was a prospective descriptive analysis, to identify if graduate assistant ACIs perceive themselves to be prepared to supervise undergraduate 
ATSs during their clinical education experience. This research included a 48-item online questionnaire, that explored demographic information, learning styles, ACI responsibilities, evaluation and feedback of student performance, and ACI preparation. Participants

A total of one-hundred-seventy-eight undergraduate CAATE accredited athletic training education programs (ATEP) were contacted with 27 institutions agreeing to participate. Of those 27 institutions there were a possible 140 novice graduate assistant ACIs that were eligible to participate. Of those, 33 novice graduate assistant ACIs completed the electronic questionnaire for a return rate of $23.5 \%$. Participants in this study were graduate assistant ACIs at an institution that has a CAATE accredited undergraduate athletic training education program for five years or more. The participants were graduate assistant ATC that have attended an ACI training workshop at their respective institution and had one year of clinical experience. The participant had the responsibility of supervising and evaluating ATSs. The participants that were excluded were those institutions who do not have graduate assistant ATCs supervising undergraduate ATSs, a CAATE undergraduate ATEP for less than five years, and if the position is a one year internship. Participants were excluded if the ACIs at the above mentioned institutions are not considered to be a novice graduate assistant ACI according to the definition of the study. The study was approved by the Office of Research Compliance, at West Virginia University.

Instrumentation

This questionnaire was created according to the researcher's objectives and content included in ACI training workshop, the current clinical education literature, and 
best clinical practice. The questionnaire consisted of two sections: demographic and content. The demographic information consisted of questions inquiring if they are a graduate student, if they are an ACI, years as an ACI, number of years as an ATC, current clinical placement/ setting, number of ATSs that the individual is supervising, if the ACI is supervised by another ACI, if they are directly supervised by a staff ATC, and whether or not the participant was supervised by an ACI during his/ her undergraduate clinical education. The content consisted of questions regarding the perceived preparedness of the ACI to supervise ATSs in the clinical setting and included questions regarding learning styles, ACI responsibilities, evaluation and feedback of student performance, ACI preparation, and overall preparedness.

The questionnaire was pilot tested by two CAATE undergraduate program directors and five ATCs at National Collegiate Athletics Association Division I, II, III institutions for readability and clarity. A psychometric statistical expert experienced in questionnaire development also viewed the questionnaire for face and content validity. Several drafts of the questionnaire were created and revisions were made following feedback from the pilot study. Procedures

Selection of the participants began by identifying higher education institutions with an ATEP that has been accredited for five or more years. From those institutions $(\mathrm{n}=178)$, the investigator obtained the undergraduate program directors (PD) name and $\mathrm{E}$ mail address. Once determined, an E-mail was sent to the undergraduate PD's institutions inquiring 1) whether they have novice graduate assistant ACIs supervising 
their ATSs; 2) the number of graduate assistants ACIs supervising ATSs; and 3) if they were interested in participating in the study.

Once the PD agreed to participate in the study, information was sent via E-mail to the undergraduate PD through West Virginia University. This E-mail consisted of a cover letter explaining the study in more detail and had a link to the questionnaire. The PD was asked to forward it to all of his or her graduate assistant novice ACIs for completion. Each of the graduate assistant novice ACIs were asked to follow the link to the questionnaire. If willing to participate, the graduate assistant novice ACI then completed the questionnaire by either clicking on the best corresponding answer or ranking of the answers. At the end of the questionnaire they were asked to finish it by clicking the submit button. If the graduate assistant novice ACIs were not willing to participate, he/she simply did not return the questionnaire to the researcher.

The participating undergraduate institutions were contacted again by E-mail two weeks later as a reminder to forward the cover letter to their novice graduate assistant ACIs. The cover letter was E-mailed once in the month of February and then two weeks following, which was the second week of March. The data were returned to the researcher via an email that was addressed as anonymous for the confidentiality of the participants. The information that was returned was then placed into an Excel spreadsheet for future analysis.

The online questionnaire was housed on the university server, which, by using a firewall, protects data in transit from outside observation. The results of the questionnaire were automatically processed by a Common Gateway Interface (CGI) server, which is also protected by the firewall and is accessible only to two university Web masters. The 
data were processed in the working memory of the CGI server and were not stored to disk; after being processed the data no longer exist on the CGI server. The CGI server automatically sent the data via E-mail to the researcher where they were saved in a locked file. Upon completion of data collection, the spreadsheet was transferred to a Universal Serial Bus (USB) drive that was kept in a locked drawer and the data were then deleted from the researcher's E-mail account.

Statistical Analysis

For the data analysis, the questionnaire was divided into five sections (demographic characteristics, learning styles, ACI responsibilities, evaluation and feedback of student performance, and ACI preparation). Responses of the graduate assistant novice ACIs at the CAATE accredited institutions were analyzed using descriptive statistics. This included frequencies and percentages of responses for the questionnaire item. All data was analyzed using SPSS Version 14.0 for Windows. (SPSS Inc. Chicago, IL.)

\section{RESULTS}

There were 178 total E-mails sent to undergraduate CAATE program directors asking for their willingness to participate. After the initial E-mail, there were 19 program directors that agreed to participate. After the second E-mail, eight more schools agreed to participate, making a grand total of 27 undergraduate programs that were willing to participate in the study. Thirteen programs declined participation secondary to not meeting the inclusion criteria. From the 27 programs that agreed to participate, 33 of the possible $140(n=33)$ individuals completed the questionnaire for a return rate of 23.5\%. Demographic Characteristics 
Of the 33 participants, all were graduate students and were an ACI at their respective institutions. Forty six percent $(n=15)$ had less than one year of experience as an ACI, (36.4\%, $\mathrm{n}=12)$ were certified athletic trainers for two years, $(72.7 \%, n=24)$ were currently working in the college / university setting, and (45.5, $n=15)$ supervised three to four undergraduate ATSs. Seventy percent $(n=23)$ of the participants are in a setting where other ACIs are also supervising ATSs, and (69.7\%, $n=23)$ reported being directly supervised on a daily basis by a staff ATC. Fifty-five percent $(n=18)$ of the participants were supervised by a graduate assistant ACI during their own undergraduate experience. Refer to Table D1 for additional demographic characteristics. Learning Styles

Of the 33 participants, $87.9 \%(n=29)$ either strongly agreed $(51.5 \%, n=17)$ or agreed (36.4\%, $n=12$ ) that the various learning styles were presented during their ACI training workshop. Seventy-nine percent $(n=26)$ strongly agreed $(30 \%, n=10)$ or agreed (49\%, $n=16)$ that information they received on learning styles during the ACI training workshop prepared them to identify the different learning styles utilized by ATSs. In addition, $75.7 \%(n=25)$ strongly agreed $(21.2 \%, n=7)$ or agreed $(54.5 \%, n=18)$ with being confident that their clinical instruction was tailored to fit the learning style of the ATS. Seventy-six percent $(n=25)$ strongly agreed $(24 \%, n=8)$ or agreed $(52 \%, n=17)$ that they were able to differentiate between learning style and teaching style. Refer to Table D2 for all responses regarding the learning style.

ACI Responsibilities

All participants $(n=33)$ strongly agreed $(33.3 \%, n=11)$ or agreed $(66.7 \%, n=22)$ that they possessed the clinical skills needed to serve as an effective ACI, and strongly 
agreed $(27.3 \%, n=9)$ or agreed $(72.7 \%, n=24)$ that they possessed the clinical knowledge needed to serve as an effective ACI. Ninety-seven percent ( $\mathrm{n}=32)$ strongly agreed $(45.5 \%, n=15)$ or agreed $(51.5 \%, n=17)$ that they were adequately able to serve as a professional mentor. Ninety-four percent $(n=31)$ strongly agreed $(42.4 \%, n=14)$ or agreed $(51.5 \%, \mathrm{n}=17)$ that they were confident in demonstrating legal and ethical behavior, and $81.8 \%(\mathrm{n}=27)$ strongly agreed $(33.3 \%, \mathrm{n}=11)$ or agreed $(48.5 \%, \mathrm{n}=16)$ that they were prepared to handle a situation involving an ATS and improper or ethical behavior in their clinical setting. Ninety-seven percent $(\mathrm{n}=32)$ strongly agreed $(36.4 \%$, $\mathrm{n}=12)$ or agreed $(60.6 \%, \mathrm{n}=20)$ that they were confident in their communication skills, $93.9 \%(\mathrm{n}=31)$ strongly agreed $(30.3 \%, \mathrm{n}=10)$ or agreed $(63.6 \%, \mathrm{n}=21)$ that they were confident in their overall supervisory skills, $96.9 \%(n=32)$ strongly agreed $(24.2 \%, n=8)$ or agreed $(72.7 \%, \mathrm{n}=24)$ that they were confident in their over all instructional skills, and $90.9 \%(n=30)$ strongly agreed $(33.3 \%, n=11)$ or agreed $(57.6 \%, n=19)$ that they were confident in their overall evaluation skills. Eighty-eight percent (n=29) strongly agreed $(33 \%, \mathrm{n}=11)$ or agreed $(55 \%, \mathrm{n}=18)$ that they were prepared to handle a situation involving an ATS and an improper or compromising interpersonal relationship in their clinical setting. Ninety-one percent $(n=30)$ strongly agreed $(27 \%, n=9)$ or agreed $(64 \%$, $\mathrm{n}=21$ ) to having a good understanding of their institutions policies and procedures to serve as an ACI and, $81.8 \%(\mathrm{n}=27)$ strongly agreed $(21.2 \%, \mathrm{n}=7)$ or agreed $(60.6 \%$, $\mathrm{n}=20$ ) to feeling confident in the use of their institutions' evaluation tools. Eighty-eight percent of the participants, $(\mathrm{n}=29)$ strongly agreed $(21 \%, \mathrm{n}=7)$ or agreed $(67 \%, \mathrm{n}=22)$ that they feel confident in performing a constructive self-evaluation of their skills and 
performance as an ACI. Refer to Table D3 for all responses regarding ACI responsibilities.

Evaluation and Feedback of Student Performance

Seventy-nine percent $(n=26)$ either strongly agreed $(39.4 \%, n=13)$ or agreed $(39.4 \%, \mathrm{n}=13)$ that the ACI felt prepared to evaluate their ATS's first clinical proficiency. All of the participants ( $\mathrm{n}=33$ ) strongly agreed or agreed that they felt confident evaluating an ATS's clinical knowledge, (48.5\%, n=16; 51.5\%, n=17, respectively) and clinical skills (42.4\%, n=14; 57.6\%, n=19, respectively). Eighty-eight percent ( $n=29)$ strongly agreed $(45.4 \%, \mathrm{n}=15)$ or agreed $(42.4 \%, \mathrm{n}=14)$ that they felt confident evaluating an ATS's professional behavior, and 90.9\% ( $\mathrm{n}=30)$ strongly agreed $(33.3 \%, \mathrm{n}=11)$ or agreed $(57.6 \%, \mathrm{n}=19)$ that they felt confident in evaluating an ATS's clinical decision making. Eighty-nine percent $(n=31)$ strongly agreed $(48.5 \%, n=16)$ or agreed $(45.5 \%, n=15)$ that they felt prepared to give effective positive feedback, and 97.0\% ( $\mathrm{n}=32)$ strongly agreed $(45.5 \%, \mathrm{n}=15)$ or agreed $(51.5 \%, \mathrm{n}=17)$ that they felt prepared to give effective constructive feedback to an ATS to improve his or her performance. All of the participants ( $\mathrm{n}=33)$ strongly agreed $(48.5 \%, \mathrm{n}=16)$ or agreed $(51.5 \%, \mathrm{n}=17)$ that they felt confident in providing students feedback on clinical knowledge, 97.0\% ( $\mathrm{n}=32)$ strongly agreed $(45.5 \%, \mathrm{n}=15)$ or agreed $(51.5 \%, \mathrm{n}=17)$ that they felt confident in providing students feedback on clinical skills, and $91.0 \%(n=30)$ strongly agreed $(45.5 \%, n=15)$ or agreed $(45.5 \%, \mathrm{n}=15)$ that they felt confident in providing students feedback on professional behavior; $94.0 \%(\mathrm{n}=31)$ strongly agreed $(45.5 \%, \mathrm{n}=15)$ or agreed $(48.5 \%$, $\mathrm{n}=16$ ) that they felt confident in providing students feedback on clinical decision making. Sixty-one percent $(\mathrm{n}=20)$ of participants indicated feeling most confident in evaluating an 
ATS's clinical skills; while 21\% (n=7) indicated being most confident in evaluating clinical decision making. Only $12 \%(n=4)$ indicated being most confident in evaluating clinical knowledge and 6\% $(\mathrm{n}=2)$ indicated being most confident in evaluating professional behavior. Sixty-seven percent $(\mathrm{n}=22)$ of participants indicated feeling most confident in providing feedback for an ATS's clinical skills; while 12\% $(n=4)$ indicated being most confident in providing feedback in clinical decision making; $12 \%(\mathrm{n}=4)$ indicated being most confident in providing feedback in clinical knowledge; and 9.1\% $(\mathrm{n}=3)$ indicated being most confident in providing feedback in professional behavior.

Refer to Table D4 for all results on evaluation and feedback of student performance.

\section{ACI Preparation}

Eighty-eight percent $(\mathrm{n}=29)$ either strongly agreed $(30.3 \%, \mathrm{n}=10)$ or agreed $(57.5 \%, \mathrm{n}=19)$ to being aware of the characteristics of an effective clinical instructor, and $78.8 \%(\mathrm{n}=26)$ strongly agreed $(15.2 \%, \mathrm{n}=5)$ or agreed $(63.6 \%, \mathrm{n}=21)$ to being able to utilize these characteristics to become a better ACI. Seventy-nine percent $(\mathrm{n}=26)$ strongly agreed $(48.5 \%, \mathrm{n}=16)$ or agreed $(30.4 \%, \mathrm{n}=11)$ to understanding the "Teaching Over Time” concept. Seventy-nine percent $(\mathrm{n}=26)$ strongly agreed $(24.4 \%, \mathrm{n}=8)$ or agreed $(54.5 \%, \mathrm{n}=18)$ that their institutions ACI training workshop prepared them to be an effective ACI in their first year, and 75.7\% ( $\mathrm{n}=25)$ strongly agreed $(33.3 \%, \mathrm{n}=11)$ or agreed $(42.4 \%, \mathrm{n}=14)$ that their institution's ACI training workshop was beneficial to them as an ACI. Eighty-eight percent $(n=29)$ strongly agreed $(39.4 \%, n=13)$ or agreed (48.4\%, $\mathrm{n}=16)$ that an ATC with one year of clinical experience and completion of an ACI training workshop could serve as an ACI. Refer to Table D5 for additional information of the percentages of responses of ACI preparation. 
When asked to rate their performance in their first year of being an ACI (0 being worst performance and 10 being the best performance) the mean score reported was 6.97 \pm 1.2 and the range was 4 to 10 . Participants were asked to rank the three greatest challenges of being a first year ACI. Of the 33 participants, 5 participants did not complete this question, therefore there were only 28 usable responses $(n=28)$. The greatest challenges the ACI experienced were time constraints $(69.7 \%, n=23)$, controlling the learning environment (57.6\%, $\mathrm{n}=19)$, and understanding institutional policies and procedures (39.4, $n=13)$. Greatest challenges as reported by participants are reported in Figure D1.

\section{DISCUSSION}

The purpose of the study is to determine the perceived preparedness of graduate assistant novice ACIs in the supervision of undergraduate ATSs in clinical education. The participants were second year graduate students, met the minimum requirements set forth by the CAATE Standards for the Accreditation of Entry-Level Athletic Training Education Programs ${ }^{4}$ to be an ACI, and had the responsibility of supervising undergraduate ATSs. To date, there are no known studies examining the preparedness of novice graduate assistant ACIs in clinical education.

The hypotheses of the study were: 1) that the novice graduate assistant approved clinical instructor will feel sufficiently prepared to be an adequate approved clinical instructor based on responses from the questionnaire and 2) the novice graduate assistant approved clinical instructors will feel that the approved clinical instructor training workshop was adequate to prepare them to supervise ATSs based on responses from the 
questionnaire. Based on the frequencies of the responses, both of the hypotheses were accepted.

Overall, the participants were comfortable with learning styles that ATSs utilize in their clinical education and with the responsibilities that are associated with being an ACI. For example, all of the participants felt they possess the clinical skills and knowledge needed to be an effective ACI. In addition, $97 \%$ of the participants felt confident in being a professional mentor. This latter finding is important because of the results from studies by Laurent and Weidner ${ }^{9}$ and Lauber et al. ${ }^{10}$. Laurent and Weidner ${ }^{9}$ investigated helpful CI characteristics perceived by CIs and ATSs. They found that the most helpful category of CI was modeling professional behavior. This category consists of the CI being involved with the students, being clear and organized, emphasizing problem solving, mentoring, having sound communication skills, having a positive attitude, and providing good feedback. ${ }^{9}$ In addition, according to these authors the top ten characteristics deemed important were displaying confidence, demonstrating respect for the students, managing clinical emergencies well, providing opportunities for the student to practice both technical and problem-solving skills, demonstrating skills for the ATS, knowing limitations by admitting when he/or she does not know something, discussing practical application of knowledge and skills, remaining accessible to the ATS, communicating effectively with the students by telling the ATS his or her expectations of them, and listening attentively to the ATS and the athletes. ${ }^{9}$

Lauber et al., ${ }^{10}$ studied PDs' and CIs’ perceptions of important CI behavior categories in athletic training clinical instruction, and they found that both the PDs and CIs identified professional behavior as a very important CI behavior. They also found 
that serving as a professional role model is very important behavior in the delivery of athletic training clinical instruction. ${ }^{9}$ The authors reported this to be true in other healthcare professions such as nursing. ${ }^{10}$ Craig, ${ }^{11}$ reported that each of the ACI's will demonstrate professionalism differently and therefore selecting the most professional ACI is a critical component for optimal development of professional behavior in ATS.

The participants overall reported confidence in evaluating ATSs and providing both positive and constructive feedback. However, more participants reported being most confident in evaluating and providing feedback on ATSs' clinical skills. This is interesting in that the participants, who responded to the questionnaire, mostly felt prepared to be an ACI in their novice years. This is in direct contrast to the Stemmans and Gangstead ${ }^{7}$ study in which they identified that ATCs in their initial clinical instructor experiences tend to lack necessary clinical-instruction knowledge, skills, and abilities to facilitate ATS behaviors in the clinical setting.

Furthermore, only six percent of the participants reported feeling most confident in evaluating professional behaviors, and only nine percent reported feeling most confident in providing feedback on professional behavior. Given the vast range of ATS professional behaviors, such as level of emotional maturity, competency, and commitment, ACIs need to be able to adjust their leadership styles or strategies to best fit the students' observed needs in specific situations. ${ }^{12,13}$ This suggests that an ACI may need more training in evaluating and providing feedback in the area of professional behavior. Wolff-Burke, ${ }^{14}$ examined professional behaviors of physical therapy students. She reported that students should possess 1) basic professional skills (such as dressing appropriately to clinical setting, having good time management, being honest and ethical, 
having polite manners, and honoring confidentiality); 2) showing maturity (such as being confident, making patients feel comfortable, and being a "team player"); 3) being business-like (view the rotation as a job), and 4) demonstrating competence appropriate to educational level. The results from her study can provide tangible professional behavior for ACIs to evaluate and provide feedback. They can also be integrated into ACI training workshop.

While most of the participants indicated that the ACI training workshop provided adequate preparation and was beneficial, 21\% reported that the workshop did not provide adequate preparation and $24 \%$ reported that it was not beneficial to them as a novice ACI. With the importance of the ACIs' roles in the ATS's clinical education, one would expect that the training workshop would provide adequate preparation and be more beneficial for all participants. However, in this small study this was not the case. The results of this study do not provide reasons why some participants believe they did not receive adequate preparation, but perhaps it could be due to the length of the workshop (four-hour minimum) or because the course is tailored to fit the needs of the institution, rather than meeting needs of individual ACIs. One of the participants responded, "The first workshop I attended was completely unhelpful (it was part of the GA orientation and was less then 10 minutes) they basically just handed me a book." The credentialing of ACIs was developed and first conducted in June of 2000 and is still a relatively new practice in athletic training clinical education. ${ }^{1,8,13}$

It is not uncommon to find that CIs in allied health professions do not have formal preparation in education and have been selected because of their professional skills rather than their teaching abilities. ${ }^{6}$ Therefore, the purpose of the ACI training workshop is to 
prepare these individuals to be able to teach, provide feedback, and evaluate athletic training clinical proficiencies. ${ }^{1}$ Identifying reasons why ACIs did not feel the course was beneficial was not the focus of this study and could be an area of potential future research.

The participants overall reported being the most confident in evaluating ATSs $(60.6 \%, n=20)$ and providing feedback $(66.7 \%, n=22)$ in clinical skills, rather than evaluating $(12.1 \%, \mathrm{n}=4)$ or providing feedback $(12.1 \%, \mathrm{n}=4)$ in clinical knowledge. Clinical knowledge is the basis of why a clinician performs a special test or provides any treatment (i.e. clinical skills). What good is it if the ATS can perform a Lachman's test to examine the integrity of the anterior cruciate ligament and not know why this test is performed further more understanding how to interpret the test. The ACI only has the knowledge from previous experience, or from what is provided through the clinical proficiencies. One of the participants responded, "I feel that the lack of independent clinical experience, as well as limited experience from one source (undergraduate institution), limits my ability to effectively evaluate and provide good feedback. I was trained in one method of handling a situation, which may not be the best, but it is the only one I know, and therefore, until I have more experience, that is how I will teach.” This then leads to the question about the clinical proficiencies concentrating more on the ATS ability to perform the test, understand the test or the opportunity to demonstrate clinical decision making in clinical education. Clinical decision making is included in the proficiencies via scenarios and real life "hands-on" application but not all ATS will be provided the same clinical education. This however was not the focus of the study and was based on assumptions in interpreting the responses. 
The participants reported that their three greatest perceived challenges in their initial years of being an ACI were time constraints, controlling the learning environment, and understanding their institutions’ policies and procedures. Of the top three greatest challenges, "time constraints" was the greatest challenge reported by the participants. This finding is consistent with Weidner et al., ${ }^{15}$ who examined students' perceptions of the type and amount of supervision received during clinical education. These authors concluded that there was an increasing difficultly for today's athletic trainer to find adequate time to accept the extra responsibility for educating the ATSs, hence limiting the ATS clinical experience. ${ }^{15}$

The next challenge that was reported was the ability of the ACI to control the ATS's learning environment. Weidner and Laurent, ${ }^{16}$ noted characteristics of a desirable learning environment in the clinical education setting and reported that there should be good management, high staff morale, harmonious working relationships, and sound interdisciplinary athlete or patient management procedures. ${ }^{17}$ They also reported that “less tangible characteristics for learning environments included personnel receptiveness, a variety of expertise, interest in newer techniques, and involvement with other professionals outside of athletic training.”16 An active learning environment provides sufficient learning opportunities for the ATS to gain valuable experience. ${ }^{16}$

The third perceived greatest challenge was for the ACI to understand his or her institutional policies and procedures. This challenge is one of the content areas set forth by the CAATE Standards for the Accreditation of Entry-Level Athletic Training Education Programs. ${ }^{4}$ It is up to the institution to develop the policies and procedures, and this should be included and discussed in the ACIs training workshop. To avoid this 
becoming a challenge in the future, novice ACI graduate assistants ATCs need a clearer understanding of the institutions policies and procedures to be able to adequately supervise the ATSs at that institution. This would allow novice ACI graduate assistants ATCs from other CAATE accredited programs alternate solutions to resolve problems when they arise at that institution.

This study had some limitations in which are relevant to results of this study. One limitation is that these finding may only be generalizable to individuals at CAATE accredited undergraduate programs being accredited for more than five years. The results from this study can not be generalized to other graduate assistants assuming the role of an ACI. The results of the questionnaire are solely the opinions of the chosen graduate assistant novice ACI at select institutions who chose to participate and these individuals may be very interested in clinical education and chose to participate. Individuals without a strong interest in ATS clinical education may have opted not to participate. Another limitation of this study is the small sample size. Of the possible 140 participants, 33 participants completed the questionnaire for a return rate of $23.5 \%$. This was a sample of convenience. The response rate for the institutions that participated was only $15 \%$. As this was the first study to determine the perceived preparedness of graduate assistant novice ACIs in the supervision of undergraduate ATSs in clinical education, additional research should be conducted in this area.

\section{CONCLUSION}

Based on the information gathered from this study, it has been determined that of the participants who responded to the questionnaire, mostly felt prepared to be an ACI in their novice years. Evaluating and providing feedback on professional behaviors may be 
a weakness among novice ACIs and may be an area that can be strengthened in the ACI training workshop. Most of the participants felt that that ACI training workshop was beneficial but there was about one-quarter of the participants who felt that the training workshop was not beneficial to their development as an ACI. The participants of the study reported that the three greatest challenges to be time constraints, controlling the learning environment, and understanding their institutions policies and procedures.

Clinically this study can assist the PD and CIE at the various institutions to have a better understanding of the novice ACI's strengths and weaknesses. This can also help direct the CIE at the institutions when constructing the ACI training workshop. Recommendations to improve the workshop based on the results include providing more information regarding evaluating and providing feedback on ATS professional behavior, managing time in the learning environment (i.e. athletic training room or other clinical site), and add more to the ACI training workshop so that all of the novice ACIs understand the institutions policies and procedures and feel prepared to work with ATSs. 


\section{REFERENCES}

1. Weidner TG, Henning JM. Historical perspective of athletic training clinical education. J Athl Train. 2002;37(4 Supplement):S-222-S-228.

2. Jarski RW, Kulig K, Olson RE. Clinical teaching in physical therapy: student teacher perceptions. Phys Ther. 1990;70(3):173-178.

3. CAATE clinical education terminology. http://nataec.org/AcademicPrograms/ProfessionalEducationentrylevel/ClinicalEd ucationResources/tabid/106/ctl/Details/mid/413/ItemID/12/Default. Accessed July 10, 2007.

4. Standards for the accreditation of entry-level athletic training education programs. Available at: http://caate.net/ss_docs/standards.6.8.2006.pdf. Accessed July 10, 2007.

5. Mensch JM. Professional responsibility and approved clinical instructors. Athl Ther Today. 2006;11(4):49-51.

6. Weidner TG, Henning JM. Being an effective athletic training clinical instructor. Athl Ther Today. 2002;7(5):6-11.

7. Stemmans CL, Gangstead SK. Athletic training students initiate behaviors less frequently when supervised by novice clinical instructors. J Athl Train. 2002;37(4 upplement):S-255-S-260.

8. Weidner TG, Henning JM. Importance and applicability of approved clinical instructor standards and criteria to certified athletic trainers in different clinical education settings. J Athl Train. 2005;40(4):326-332.

9. Laurent T, Weidner TG. Clinical instructors' and student athletic trainers' perceptions of helpful clinical instructor characteristics. J Athl Train. 2001;36(1):58-61.

10. Lauber CA, Tith PE, Leary PA, Martin D, Killian CB. Program directors' and clinical instructors' perception of important clinical-instructor behavior categories in the delivery of athletic training clinical instruction. J Athl Train. 2003;38(4):336-341.

11. Craig DI. Learning professionalism in athletic training education. Athl Train Edu J. 2006;1(Jan-Mar):8-11.

12. Platt Meyer L. Athletic training clinical instructor as situational leaders. J Athl Train. 2002;37(4 Supplement):S-261-S-265. 
13. Weidner TG, Henning JM. Development of standards and criteria for the selection, training, and evaluation of athletic training approved clinical instructors. J Athl Train. 2004;39(4):335-343.

14. Wolff-Burke M. Clinical instructors'descriptions of physical therapist student professional behavior. J Phys Ther Edu. 2005;19(1):67-76.

15. Weidner TG, Noble GL, Pipkin JB. Athletic training students in the college/ university setting and the scope of clinical education. J Athl Train. 2006;41 (41):422-426.

16. Weidner TG, Laurent T. Selection and evaluation guidelines for clinical education settings in athletic training. J Athl Train. 2001;36 (1):62-67.

17. Laurent T, Weidner TG. Clinical-education setting standards are helpful in the professional preparation of employed, entry-level certified athletic trainers. J Athl Train. 2002;37 (4 Supplement):S-248-S-254. 
APPENDICES 


\section{APPENDIX A}

\section{THE PROBLEM}

\section{Research Question}

Standards and guidelines are established by the Commission on Accreditation of Athletic Training Education (CAATE). ${ }^{3}$ One of the main changes in athletic training clinical education that has occurred is progression from the internship route towards a standardized curriculum amongst all CAATE accredited programs. In 1959, an athletic training student needed to fulfill laboratory/ practical experience of only six semester hours or its equivalent. ${ }^{18}$ Then in the mid 1970s that changed to 600 total clock hours under the supervision of a National Athletic Trainers’ Association (NATA) certified athletic trainer. ${ }^{18}$ In the early 1980s, the first athletic training major was added, but not all prospective athletic trainers had to attend a curriculum-based program or receive a degree in Athletic Training to become a certified athletic trainer. ${ }^{18}$ Instead, they could become a certified athletic trainer via the internship route where they had to complete 1500 clock hours under the supervision of an NATA-certified athletic trainer and complete two athletic training classes. Currently, to sit for the certification exam, an athletic training student must attend and graduate from a CAATE accredited athletic training education program. ${ }^{3}$ With the new clinical requirement for the ATSs in their clinical experience, the demand for qualified clinical instructors to educate the students has increased.

A clinical instructor (CI) is an individual identified to supervise athletic training students during their clinical experience. ${ }^{3}$ An approved clinical instructor (ACI) performs the same supervision as a CI but has received the appropriate professional 
credentials after training by the institutions clinical instructor educator (CIE). To become an ACI, an individual must be an ATC for a minimum of one year and have taken the ACI training course at his or her institution. ${ }^{3}$ Prior to the 2002 - 2003 academic year all instructors were considered clinical instructors as there were no clinical proficiencies to evaluate. Now, an ACI is responsible for evaluating proficiencies. ${ }^{3}$ Many of the current ACIs educating the undergraduate athletic training students are considered novice ACIs. A novice ACI has been an ATC at least one year and has at least one year of clinical experience. ${ }^{19}$ In addition to supervising the students, the ACI provides instruction and evaluation of the athletic training educational competencies and/or clinical proficiencies. ${ }^{3}$ The ACIs are the individuals responsible for creating an optimal clinical educational experience for the ATS.

There is inadequate published literature on the effectiveness of the credentialing process for ACIs. The only data published are the criteria needed to become an ACI, ${ }^{4}$ helpful characteristics that a good clinical instructor should exhibit, ${ }^{9}$ the importance of the standards and criteria of ACIs in different clinical settings and how they apply, ${ }^{8}$ and the program director and clinical instructors’ perception of important behaviors in the delivery of clinical education. ${ }^{10}$

Three studies have examined clinical instruction. All studies examined the characteristics that a good CI should exhibit. Laurent and Weidner ${ }^{9}$ focused on the students perceptions, while Lauber et $\mathrm{al}^{10}$ focused on perceptions of the program directors and CI's, and Weidner and Henning, ${ }^{8}$ focused on ACI's perceptions.

These studies all focus on similar characteristics; however there are some variations among the studies. Laurent and Weidner ${ }^{9}$ focused on the students' perception 
of helpful characteristics. Weidner and Henning, ${ }^{8}$ examined seven guidelines and criteria: legal and ethical behavior, communication skills, interpersonal relationships, instructional learning, supervisory and administrative skills, student performance evaluation, and clinical skills and knowledge. Lauber et al. ${ }^{10}$ focused on five categories: instructional, interpersonal, evaluative, professional, and personal.

Laurent and Weidner ${ }^{9}$ stated that the most important characteristics for CIs identified by athletic training students (ATS) were modeling and humanistic orientation. Weidner and Henning, ${ }^{8}$ on the other hand reported that legal and ethical behavior was the most important characteristic reported by the ACI's. Lauber et al. ${ }^{10}$ revealed that instructional, interpersonal, evaluative, professional, and personal characteristics were all important behaviors and should be used in clinical education of ATS but the perception of each group varied.

Based on the content of the above studies, only Weidner and Henning ${ }^{8}$ focused on the perception of the ACI. The other authors focused on the ACI's preparedness to enter the realm of clinical education. There should be more than one study to focus on the ACIs perception of various aspects of athletic training clinical education. The proposed study will demonstrate the ACIs perceived preparedness to supervise and evaluate ATSs. There is minimal data in the literature on graduate assistant ATC's, especially novice ACIs.

With all of the data published on clinical education and CI's characteristics and attributes, there is little to no research on the adequacy of the ACI credentialing process in the education of undergraduate students. 
Therefore my research question is, with the amount of current training required to become an ACI, what is the perceived preparedness of the novice graduate assistant ACI in the supervision of undergraduate ATSs?

Experimental Hypotheses

1. Novice graduate assistant approved clinical instructor will feel sufficiently prepared to be an adequate approved clinical instructor based on responses from the questionnaire.

2. Novice graduate assistant approved clinical instructors will feel that the approved clinical instructor training workshop was adequate to prepare them to supervise ATSs based on responses from the questionnaire.

Assumptions

1. All subjects will answer all questions openly, honestly, and to the best of their ability.

2. The questionnaires that will be used are assumed to be reliable and valid.

3. The participants will complete and return the questionnaires in a timely manner.

Delimitations

1. Due to the number of Commission on Accreditation of Athletic Training Education accredited undergraduate programs being accredited for 5 or more years, results may not be generalizable to the entire population.

2. The results of the questionnaire was based solely on the opinions of the chosen graduate assistant novice approved clinical instructors at select institutions.

3. The results from this study can not be generalized to other graduate assistants assuming the role of an approved clinical instructor.

Operational Definitions

1. Ability to Intervene- The CI or ACI is within the immediate physical vicinity and interact with the ATS on a regular and consistent basis in order to provide direction and correct inappropriate actions. The same as being "physically present."3

2. Allied Health Care Professional- Physician Assistants, physical therapists, registered nurses, doctors of dental surgery, and other health care professionals, recognized by the AMA/AOA as allied health professionals, who are involved in direct patient care and are used in the didactic and clinical education portions of the ATEP. These individuals may or may not hold formal appointments to the instructional faculty. ${ }^{3}$ 
3. Approved Clinical Instructor (ACI)- An appropriately credentialed professional identified and trained by the program CIE to provide instruction and evaluation of the Athletic Training Educational Competencies and/or Clinical Proficiencies. The ACI may not be a current student within the ATEP.

4. ATEP- Athletic Training Education Program. ${ }^{3}$

5. Athletic Training Student (ATS)- A student enrolled in the athletic training major or graduate major equivalent. $^{3}$

6. Certified Athletic Trainer (ATC)- Works with physicians and other medical personnel, employers, patients, parents, guardians, and athletic personnel in the development and coordination of efficient and responsive health care delivery systems. Athletic trainers are integral members of the health care team in secondary schools, colleges and universities, professional sports programs, sports medicine clinics, corporate/industrial, and other health care settings., 24

7. Clinical Coordinator- The individual program may designate a certified athletic trainer as having the primary responsibilities for the coordination of the clinical experience activities associated with the ATEP. The clinical coordinator position is currently recommended, but not required by the Standards. ${ }^{3}$

8. Clinical Education- The application of knowledge and skills learned in didactic and laboratory settings, to actual practice on patients under the supervision of an ACI/CI. 1, 3, 8, 9, 10, 12, 13, 15, 16, 18, 19, 20, 22, 25, 26, 27, 28, 29

9. Clinical Experience- Those clinical education experiences for the Athletic Training Student that involve patient care and the application of athletic training skills under the supervision of a qualified instructor. ${ }^{3}$

10. Clinical Instruction Site- The location in which an ACI or CI interacts with the ATS for clinical experiences. If the site is not in geographical proximity to the ATEP, then there must be annual review and documentation that the remote clinical site meets all educational requirements. ${ }^{3}$

11. Clinical Instructor- An individual identified to provide supervision of athletic training students during their clinical experience. An ACI may be a CI. The ACI may not be a current student within the ATEP. 1, 2, 3, 6, 7, 9, 10, 12, 15, 20, 25, 26, 27, 28, 30, 31, 32, 33

12. Clinical Instructor Educator (CIE)- The BOC Certified Athletic Trainer recognized by the institution as the individual responsible for ACI training. If more than one individual is recognized as a CIE for an ATEP, then at least one of those individuals must be a BOC Certified Athletic Trainer. ${ }^{3}$

13. Commission on Accredited Athletic Training Education (CAATE)- The agency responsible for the accreditation of entry-level Athletic Training educational 
programs. Their purpose is to develop, maintain, and promote appropriate minimum standards of quality of entry level Athletic Training education programs. ${ }^{3}$

14. Competencies- The education content required of entry-level athletic training programs. These competencies should be used to develop the curriculum and educational experiences of students enrolled in CAATE-accredited entry-level athletic training education program. ${ }^{3}$

15. Direct Supervision- Supervision of the athletic training student during clinical experience. The ACI and or CI must be physically present and have the ability to intervene on behalf of the athletic training student and the patient. ${ }^{3}$

16. Formal Instruction- Teaching of required competencies and proficiencies with instructional emphasis in a structured classroom and laboratory environment(s). ${ }^{3}$

17. Learning Over Time (mastery of skills)- The process by which professional knowledge and skills are learned and evaluated. This process involves the initial formal instruction and evaluation of that knowledge and skill, followed by a time of sufficient length to allow for practice and internalization of the information/skill, and then a subsequent re-evaluation of that information/skill in a clinical (actual or simulated) setting. ${ }^{3,34,35}$

18. National Athletic Trainers’ Association Post-Professional Program- Athletic training education program that prepares athletic trainers for advanced clinical practice, and research and scholarship, in order to enhance the quality of patient care, optimize patient outcomes, and improve patients' health-related quality of life., 36

19. Novice Graduate Assistant Approved Clinical Instructor (NACI)- A certified athletic trainer who has been certified for at least one year, a graduate assistant, and has one to three years of clinical experience. ${ }^{19}$

20. Proficiencies- The entry-level athletic training clinical proficiencies define the common set of skills that entry-level athletic trainers should possess and redefine the structure of clinical education from a quantitative approach to an outcome-based qualitative system. $^{3}$

21. Program Director- The full-time faculty member of the host institution and a BOC Certified Athletic Trainer responsible for the administration and implementation of the ATEP. 3, 33, 37, 38

22. Standards for the Accreditation of Entry Level Educational Programs for the Athletic Trainer (Standards)- Used to prepare entry-level athletic trainers for the development, evaluation, analysis, and maintenance of ATEPs. ${ }^{3}$

Limitations 
1. Participants in this study was limited to graduate assistant novice approved clinical instructors.

2. Participants in the study were novice graduate assistant approved clinical instructors at a Commission on Accreditation of Athletic Training Education accredited undergraduate program.

3. Selection of participants- an external validity threat based on the choice of participants as a random group or an experimentally accessible group.

4. Generalizations of findings to other settings- an external validity threat where the findings of the participants are generalized towards a target population.

Significance of the Study

With athletic training education currently undergoing reform based on the requirements of CAATE, clinical education is also experiencing changes. One crucial component of clinical education is the clinical instructors and/or the approved clinical instructors providing clinical instruction and supervision to the undergraduate ATS. With minimal preparation of ACIs, one questions whether the ATSs are receiving optimal instruction.

By gathering data from novice graduate assistant ACIs at a CAATE accredited undergraduate ATEP, one should be able to ascertain whether the current educational standards are a viable training program to properly prepare today's ACIs for entry into the professional realm of clinical education. The study should indicate whether ACIs feel they are properly prepared to supervise the prospective ATCs, or if there is additional training needed that could be provided at the graduate level of instruction. If the study reveals the necessity for additional training, further study should be made into the appropriate educational areas. Preparing ACIs now will result in better prepared ACIs in the future. 
For the profession to grow in a positive direction and to become as respected as other clinical professions, it is important for ATCs' to be aware of the importance of the clinical education of students. Therefore it is also important to determine whether the ACI training workshop is adequate for the novice graduate assistant approved clinical instructor to educate, supervise, and evaluate clinical experiences of athletic training students. If not, changes should be determined. 


\section{APPENDIX B}

\section{LITERATURE REVIEW}

Introduction

Clinical education comprises a large portion of professional preparation in athletic training and other allied health care fields. Athletic training clinical education can be described as the portion of the athletic training student's professional preparation that involves the formal acquisition, practice, and evaluation of clinical proficiencies through classroom, laboratory, and clinical experiences in medical care environments. ${ }^{1}$ Certified athletic trainers perceive that approximately 53\% of their entry-level professional development came from clinical education. ${ }^{1}$ In contrast to athletic training, physical therapy clinical education has been reported to be approximately $23 \%$ to $30 \%$ of the total curriculum. $^{2}$

Clinical teaching involves exposing a student to conditions, usually in an active patient setting, where the probability of learning clinical information is high and involves a student, a clinical instructor, and patients. ${ }^{2}$ The evolution of clinical education has placed more clinical teaching and evaluation responsibilities on certified athletic trainers who may not have had an academic focus in their professional preparation. ${ }^{6,13}$ It is not uncommon to find that allied medical clinical instructors do not have formal preparation in education and have been selected because of their professional skills rather than their teaching abilities. ${ }^{6}$ In athletic training programs, an approved clinical instructor (ACI) is an individual who is appropriately credentialed, professional identified, and trained by the program's clinical instructor educator (CIE) to provide instruction and evaluation of the athletic training educational and/ or clinical proficiencies. ${ }^{3}$ 
New educational standards require ACIs to play a much more significant role in the education of their assigned students than in previous years. ACIs must provide daily personal contact and supervision of students and be physically present in order to intervene in the delivery of health care if necessary. ${ }^{5}$ There is an increasing need identified within the profession of athletic training to provide training and development for clinical instructors. ${ }^{8}$ Some Commission on Accreditation of Allied Health Education Programs (CAAHEP) (now CAATE)-accredited athletic training education programs depend on certified athletic trainers who have less than one year of experience to provide students supervision during clinical instruction. ${ }^{7}$ Therefore, many of the current ACIs are novice in teaching as well as in the profession, and have limited or no experience in the supervision of athletic training students. The review of the literature will discuss the evolution of athletic training education, the graduate assistant ATC, ATCs, ACI / CIs, the novice ACI, and the ACI training workshop.

Historical Overview on Didactic Athletic Training Education

Athletic training education has evolved over the past five decades when the first athletic training education program appeared in the 1950s. ${ }^{18}$ In 1956, the first step in developing an athletic training education program was the appointment of the NATA Committee on Gaining Recognition, whose role "was to study avenues through which the professionalization of athletic training could be enhanced.” ${ }^{18}$ In 1959, the committee developed the first athletic training curriculum model of athletic training education, which was approved by the NATA. This curriculum was based on classes that already existed in a four-year university or college but had concentrations in the departments of physical education and health. The classes had two main areas of importance. The first 
area of importance was inclusion of classes that would help the student get his or her secondary-level teaching credentials due to the high demand for athletic trainers at the secondary school level. This would make the athletic trainer more marketable with teaching credentials in the field of physical education or health. The second area of importance was to include classes that were prerequisites for entrance into physical therapy schools. This would allow the athletic trainer to further his or her educational, improve professional growth, as well as make the individual more employable. ${ }^{18}$

In 1969, the Committee on Gaining Recognition was newly termed the Professional Advancement Committee. This newly named committee was then subdivided into the Subcommittee on Professional Education and the Subcommittee on Certification. The Professional Advancement Committee was then changed to the NATA Professional Educational Committee (NATA-PEC). The NATA-PEC was responsible for the recognition of the first undergraduate athletic training education programs. The first programs recognized were Mankato State University, Indiana State University, Lamar University, and the University of New Mexico. The recognition of these undergraduate programs also began the evaluation and approval process of the NATA athletic training curriculum. ${ }^{18}$

During the 1970's, athletic training education experienced an increase in the number of athletic training programs as well as the NATA Certification Committee administered the first national certification examination. Although the NATA-PEC did not make any drastic changes in education, they continued to review and revise the course work as well as the clinical experience requirements. With this increase in the number of athletic training programs, came an increase in the number of athletic training 
students. Having an increased number of athletic training students, decreased the need for students to take physical therapy prerequisites and more of a focus on the subject of athletic training. This increased the focus toward course work in the field of athletic training. It was now felt that a teaching degree in physical education or health was actually limiting the student's chance of obtaining employment at the secondary level. It was thought that getting a teaching degree in physical education or health was limiting opportunities for employment due to the amount of students going into the field of athletic training. However, teaching certification remained and the athletic training students continued to obtain teaching certifications in academic majors other than health and physical education.

Also during the 1970's the NATA-PEC developed a formal list of behavioral objectives that identified desired learning outcomes for the athletic training student. This was a first step towards the recognition of a more specialized body of knowledge that led to the eleven courses that served as the framework of didactic athletic training education. These courses were anatomy, physiology, physiology of exercise, applied anatomy and kinesiology, psychology, first aid and safety, nutrition, remedial exercise, health (personal, community, and school), basic athletic training, and advanced athletic training. These behaviors lead to the formation of the Competencies in Athletic Training, in the early $1980 s^{18}$

In the 1980s, the NATA Board of Directors required an approved athletic training curriculum major to be implemented. Once the major was created, the Guidelines for Development and Implementation of NATA Approved Undergraduate Athletic Training 
Education Programs were developed as the standards for the undergraduate athletic training program. ${ }^{18}$

In the 1990s, the athletic training profession met a milestone in the history of the profession. For the first time ever the American Medical Association (AMA) formally recognized the profession of athletic training as an allied health care profession. Once the profession was recognized by the AMA, the accrediting organization for the undergraduate programs changed from the NATA-PEC to the AMA Committee on Allied Health Education and Accreditation (CAHEA). This was to gain the benefits of standardized education program requirements and external peer review by a highly regarded, specialized accreditation agency. Once CAHEA became the accrediting body of athletic training, the NATA-PEC combined with CAHEA to form a review committee for entry-level allied health education programs. In 1991, the Guidelines for Development and Implementation of NATA Approved Undergraduate Athletic Training Education Programs were replaced with the Essentials and Guidelines for an Accredited Educational Program for the Athletic Trainer to meet the standards of the AMA continuing medical education. ${ }^{18}$

Once CAHEA was established, the AMA decided that the accrediting agency should be a self-supporting independent agency. With that, CAHEA, now the Commission on Accreditation of Allied Health Education Programs (CAAHEP) was recognized by the United States Department of Education as an accrediting agency for education programs. The Essentials and Guidelines for an Accredited Educational Program for the Athletic Trainer now became the Standards. ${ }^{18}$ 
On July 1, 2006, the Joint Review Committee for Athletic Training (JRC-AT) officially separated from CAAHEP (Commission on Accreditation of Allied Health Educational Programs) and became an independent specialized accreditor for athletic training, known as the Commission on Accreditation of Athletic Training Education (CAATE). All athletic training programs, formerly accredited by CAAHEP, were automatically accredited by CAATE. ${ }^{3}$ With CAATE now being the accrediting body of athletic training, accreditation of athletic training educational programs is now "inhouse.” This is the first time in approximately sixteen years that the accrediting of athletic training education programs has been returned to the profession. Historical Overview of Athletic Training Clinical Education

Clinical education is a critical component of allied health education programs, and athletic training is no exception. ${ }^{13}$ Clinical education in the health professions could be viewed as a triad involving the interplay of setting, instructor, and student. Clinical education is the portion of the curriculum in which the theoretical and practical components are integrated into real-life situations with actual athletes or patients. ${ }^{1}$ Athletic training clinical education can be described as the portion of the athletic training student's professional preparation that involves the formal acquisition, practice, and evaluation of clinical skills through classroom, laboratory, and clinical experiences in medical care environments. Clinical education involves the instruction and evaluation of these clinical skills under the direct supervision of an Approved Clinical Instructor (ACI) who has completed appropriate training. ${ }^{15}$

Clinical education has evolved since the beginning of athletic training education in 1959. In 1959, the only laboratory / clinical experience an athletic training student 
needed was six semester hours or its equivalent. Then in the 1970s, formal clinical education guidelines emerged. During this period of time, the NATA-PEC made a formal list of behavioral objectives that identified preferred learning outcomes for the athletic training student based on the 11 required courses. Instead of completing semester hours, a clinical clock-hour requirement and a skill-competency checklist were created to guide and monitor development of the students' clinical skills. However, the clinical requirements varied depending upon whether the athletic training student was in an approved curriculum program or an internship program, thus allowing two routes for certification. $^{18}$

The first route was in the context of a formal educational program (approved curriculum), whereas the other took a more "'hands on"' experiential route supplemented by a minimal amount of course work (internship). From the 1970s until the early 2000s, students became clinically eligible to take the National Athletic Trainers’ Association Board of Certification (NATABOC) certification examination by completing 600 to 800 clinical-experience hours in an approved curriculum program or 1800 clinical hours as an internship student (and later 1500 hours as an internship student.) Additionally, students in both programs were required to complete clinical experiences with contact and collision sports. ${ }^{1,18}$ In the 2004-2005 academic year, the internship route to obtain certification was eliminated. ${ }^{3}$

Currently the profession is eliminating the clinical clock hour requirements that an ATS must meet to sit for the BOC certification exam. ${ }^{4}$ While there is no mandated maximum number of clinical experience hours defined, students spending more than half of the hours of an average work day involved in athletic training student experiences ( 20 
hours/week) will be supervised by a staff certified athletic trainer. ${ }^{3}$ Athletic training students must be supervised at all times and the clinical instructor/approved clinical instructor must be able to intervene on behalf of the student and/or patient at all times. Athletic training students may perform athletic training skills only with direct supervision. Athletic training students cannot be required to perform any skills

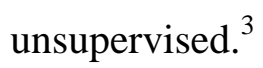

According to the CAATE Standards for Accreditation of Entry-Level Athletic Training Education Programs Standards; ${ }^{4}$ "the length of clinical experiences should be consistent with other comparable academic programs requiring a clinical or supervised practice component. Such policies must be consistent with federal or state student workstudy guidelines as applicable to the campus setting." ${ }^{4}$ The other limitation is that "consideration must be given to allow students comparable relief (days off) from clinical experiences during the academic year as compared to other student academic and student activities offered by the institution (e.g., other health care programs, athletics, clubs).”4 Another change is that the ATSs are now required to be evaluated on various competencies and proficiencies set forth by the NATA Education Council. The competencies and proficiencies were a result of the NATABOC Role Delineation Study performed by the NATABOC. ${ }^{39}$

The BOC Role Delineation Study was a study performed by the BOC to determine whether the national athletic training certification examination had content validity. ${ }^{40}$ Ensuring content validity on the BOC certification exam is one way to demonstrate that the examination appropriately evaluates the knowledge and skills required to function as a competent entry-level athletic trainer. The areas tested in the 
exam measure the knowledge and skills essential to the profession and reflect the tasks performed in the range of practice settings throughout the United States. The study shows the importance, criticality, and relevance of the practice of athletic training. ${ }^{40}$

The clinical competencies used by CAATE were created from the BOC Role Delineation Study and the NATA Education Council. ${ }^{3}$ These competencies are comprised of knowledge and skills that are required of an entry-level athletic trainer. The twelve domains in the current edition of the Athletic Training Educational Competencies are risk management, pathology, diagnosis, medical conditions, acute care, therapeutic modalities, exercise, pharmacology, psychosocial aspects, nutritional aspects, administration, and professional development. ${ }^{39}$ The Competencies are further divided into 3 different domains, cognitive competencies, psychomotor competencies, and clinical proficiencies. Each of these domains is then divided into specific competencies and proficiencies. The ATS must demonstrate both proficiency and then mastery in each of the competencies and proficiencies for the ATS to graduate and sit for the BOC certification exam. ${ }^{39}$ For a proficiency to be evaluated there must be constant visual and auditory interaction between the student and the ACI that must be maintained. ${ }^{15}$ Graduate Assistant Certified Athletic Trainer

After the completion of an undergraduate curriculum and obtaining a bachelors degree, many athletic training students search for a graduate assistantship position that provides 1) financial support; 2) opportunities for further development of clinical skills; and 3) the opportunity to earn a master's degree. Many of the undergraduate ATSs are advised to get a masters degree in an area of study other than athletic training to enhance the student's qualifications for future professional opportunities. ${ }^{36}$ The searching ATS 
can also obtain a masters degree in athletic training as well as have a graduate assistantship that will provide the above benefits. The post-professional education program in athletic training is discussed in depth below.

NATA accredited post-professional program: With the development of the undergraduate curriculums during the late 1960s, the graduate athletic training curriculums also began to emerge. The first NATA approved graduate athletic training education program was established in 1972. Then in the 1990s, the NATA-PEC launched a policy change in graduate athletic training education that for a program to be an NATA approved program, "advanced" learning experiences beyond those required for CAAHEP accreditation of an entry-level program had to be offered. With these changes, the NATABOC discontinued "completion of an NATA-approved graduate program" as a route to certification. Therefore, to gain acceptance into a NATA approved graduate level program, students had to complete all requirements to sit for the certification examination or already be a certified athletic trainer. "For accreditation to have value, it must be a meaningful indicator of quality and it must be viewed as such. The extent to which the outstanding characteristics of these new guidelines correlate with educators' concepts of quality can indicate if the new graduate education accreditation standards will be meaningful to the athletic training academic community and, therefore, sought after by potential students and employers." ${ }^{41}$ According to Seegmiller ${ }^{41}$ athletic training educators, stated that the greatest contributors to program quality were the program curriculum, adequate faculty, staff, administrative support, evaluation, clinical education, and research. 
Graduate athletic training education has its own principles and philosophy. Table 1 describes the principles of a graduate education. Graduate athletic training education is based on six principles which are listed and defined in Table 1. The post-professional graduate athletic training education program philosophy is to expand the depth and breadth of the applied, experiential, and propositional knowledge and skills of entry-level certified athletic trainers, to expand the athletic training body of knowledge, and to disseminate new knowledge in the discipline. Graduate education is characterized by advanced systematic study and experience advanced in knowledge, understanding, scholarly competence, inquiry, and discovery. ${ }^{42}$

Table 1. Principles of a Graduate Education. ${ }^{42}$ Mastery of subject matter

Facilitates mastery over the content and skills of the discipline at a level appropriate to the degree sought

Critical thinking

Theoretical understanding

Proficiency in research and/or creative activities

Service orientation

Diverse representation of perspectives
Develops and refines critical thinking skills including a thorough knowledge of the assumptions of the discipline and an understanding of viable alternative assumptions

Provides an understanding of the theoretical bases of the field of study by grounding application and performance in theory

Develops proficiencies that advance the knowledge and activities of the discipline. These proficiencies include good writing skills as well as the ability to present original insights and creative expressions

Instills responsibility to return the special benefits of graduate study to the larger community

Provides for intellectually and culturally rich encounters within the discipline; Study 
and inquiry are conducted in a context sensitive to ethnic and cultural diversity.

One of the major differences between the undergraduate and graduate level athletic training program is that graduate education has a greater emphasis on research and scientific inquiry as outlined in the Guidelines for Development and Implementation of NATA Approved Graduate Athletic Training Education Programs. ${ }^{18,36}$ According to Wilkerson et al. ${ }^{36}$ a post-professional education program should emphasize the importance of research for clinical-decision making and the development of new knowledge within the discipline.

Certified athletic training students should pursue a graduate education for multiple reasons. Ingersoll and Gieck ${ }^{43}, 44$ stated the reason to pursue graduate education was to further knowledge development in athletic training, opportunity in colleges and universities, opportunities in the high profile sports, personal fulfillment in the area of athletic training, better job opportunities in a wider array of settings, and higher salaries than certified athletic trainers with only a bachelor's degree. In graduate athletic training programs, students should learn to appreciate complexity, dichotomies, contradictions, generalizations, learn about human variability, and learn limits of their knowledge, as well as more specialized knowledge and complex skills. ${ }^{43 .} 44$ Essential skills gained from a graduate education include thinking logically, dealing with complexity, problem solving, conceptualizing and abstracting, formulating problems, creating new ideas or innovative approaches, and understanding, rather than memorizing. ${ }^{43,44}$ Athletic Trainer Certified (ATC)

A certified athletic trainer (ATC) is an individual that is a medical professional who is an expert in injury prevention, assessment, treatment and rehabilitation, 
particularly in the orthopedic and musculoskeletal disciplines. ${ }^{24}$ ATCs work with physicians and other medical personnel, employers, patients, parents, guardians, and athletic personnel in the development and coordination of efficient and responsive health care delivery systems. Athletic trainers are integral members of the health care team in secondary schools, colleges and universities, professional sports programs, sports medicine clinics, corporate/industrial, and other health care settings. ${ }^{3}$

In the past, the NATABOC has offered two routes in which an individual could follow to become an ATC. The first route was a formal curriculum and the other was an internship route. This continued until the early 2000’s. Now for an athletic training student to sit for the exam one must hold a degree from a CAAHEP (currently CAATE) accredited undergraduate athletic training program. Once the athletic training student has obtained the proper criteria; they are eligible to sit for the certification exam given by the NATABOC.

Approved Clinical Instructor/ Clinical Instructor

Success in the role of clinical instructor (CI) requires considerable attention to teaching that might not have been included in the Cl's professional education. ${ }^{6}$ CIs can supervise the ATSs during their clinical experience but they can not evaluate the ATSs on their proficiencies. Only the ACI can evaluate the ATSs on their proficiencies. ${ }^{4}$ Before the credentialing of ACIs in 2000, all CIs were known as CIs, but once the credentialing began they were now known as ACIs. In the following section: approved clinical instructor/ clinical instructor, the novice approved clinical instructor, and the approved clinical instructor training workshop will be covered. 
Approved clinical instructor(s) (ACI)/ clinical instructor(s) (CI): Under the direction of the Clinical Education Subcommittee of the NATA Education Council, Clinical Instructor Educator (CIE) seminars were developed and first conducted in June 2000. An overriding goal of the seminars was to equip athletic training program directors and clinical education coordinators with the information and resources to serve as CIEs at their institutions. The CIEs instruct ACIs to effectively teach and evaluate the athletic training clinical proficiencies to the ATSs during a structured training workshop.

In order to bring credence and validity to the educational practices of athletic training clinical instructors, it is imperative that expectations for educational practices be established and investigated by members of the profession rather than our simply borrowing and adapting practices from other allied health care professions. ${ }^{13}$ Upon completion of the workshop, the participant becomes an ACI. The ACI can provide instruction and evaluation of the ATS' clinical proficiencies. ${ }^{3}$ Requirements for completing the ACI training include 1) appropriate credentials in a health care profession as defined by the AMA or American Osteopathic Association; 2) be an ATC or appropriately credentialed health care professional for a minimum of one year; and 3) not be currently enrolled in the entry level athletic training education program at the institution. ${ }^{4}$

The responsibilities set forth by CAATE for ACIs include providing instruction and/or evaluating the Athletic Training Educational Competencies, providing assessment of athletic training students' clinical proficiency; having regular communication with the appropriate ATEP administrator; and demonstrate understanding of and compliance with the policies and procedures of the ATEP. ${ }^{4}$ 
If a CI is credentialed for less than one year, the program must develop and document the implementation of a plan for supervision of that CI by an experienced credentialed CI that ensures the quality of instruction provided to the athletic training students. ${ }^{4}$

Athletic training clinical education relies heavily on the expertise and effectiveness of clinical instructors, who serve as teachers of clinical skills, and educational leaders, who pass on leadership behaviors while teaching, supervising, and mentoring athletic training students. Given the vast range of ATS professional behaviors, such as level of emotional maturity, competency, and commitment, CIs need to be able to adjust their leadership styles or strategies to best fit the students' observed needs in specific situations. ${ }^{12,13}$

Laurent and Weidner ${ }^{9}$ have researched the CI's and ATS' perception of helpful characteristics that CIs should possess for the advancement of the ATS clinical learning experiences. The top ten characteristics deemed important were displaying confidence, demonstrating respect for the students, managing clinical emergencies well, providing opportunities for the student to practice both technical and problem-solving skills, demonstrating skills for the ATS, knowing limitations by admitting when he/or she does not know something, discussing practical application of knowledge and skills, remaining accessible to the ATS, communicating effectively with the students by telling the ATS' his or her expectations of them, and listening attentively to the ATS and the athletes. ${ }^{9}$

Effective CI characteristics have been reported in other healthcare disciplines. Tang et al. ${ }^{45}$ evaluated effective characteristics clinicians in nursing should display according to the students perceptions. The most important was the ability to develop an 
interpersonal relationship between the nursing student and the CI. The next highest ranked characteristic was the personality of the CI. The ability of the CI to effectively teach was the students' third highest ranked characteristic. The students ranked the CI's professional competence last. ${ }^{45}$

According to Cangelosi ${ }^{46}$ in accelerated second degree baccalaureate nursing programs, an effective characteristic that nursing students admire was an instructor that had both pedagogical skills and the clinical competence to show students how to implement their classroom learning in the clinical setting. ${ }^{46}$ Students believed that CIs who would "take the extra time”, create learning experiences, push the students to do their best, and who were able to bridge the ideal with the rough and offer a compromise with pragmatism were the most effective. ${ }^{46}$

Novice ACI: Novice ACIs are certified athletic trainers that meet all the qualification set forth by CAATE and have less than 1 year of clinical-instructor experience. ${ }^{4,7}$ In Stemmans and Gangstead, ${ }^{7}$ novice approved clinical instructors express a significant amount of indecision, lack pedagogic content, and demonstration ability. Novice ATCs appear to lack the requisite clinical-instruction knowledge, skills, and abilities to facilitate athletic training student behavior in a clinical setting. ${ }^{7}$ Novice ACIs were found to have less ATS-initiated interactions and affect the ATS's behavior which proves that there is an increase teaching efficacy with increased teaching experience. ${ }^{7} \mathrm{~A}$ novice ACI who is responsible for clinical instruction is less likely to be able to differentiate between a teaching patient case and a non-teaching patient case which could delay an ATS from participating in activities that a more experienced educator would promote. $^{7}$ 
Miller and Berry ${ }^{23}$ found that novice athletic training students were similar to the novice nursing students studied by Neill et al. ${ }^{47}$ Miller and Berry, ${ }^{23}$ and Neill et al., ${ }^{47}$ found that both the ATSs and nursing students were sometimes unsure of the roles they are expected to play and withdraw from active participation and then become passive observers. This is thought to happen due to differences between expected and actual roles, or it may be part of the normal cognitive development. ${ }^{23,47}$ As the students began to develop a certain level of autonomy and confidence and become familiar with their roles, they moved from passive observers to active participants during clinical placements. $^{23,47}$ This transition enables novice students to effectively engage in learning activities and promotes professional development. ${ }^{23}$

Novice nurses like ATSs in the clinical setting are expected to transform subject matter knowledge into specific performances, to develop situated understandings of theoretical concepts and are also expected to negotiate and maneuver within the ideological, professional and interpersonal agendas that characterize each of the respective professions. ${ }^{48}$ The way in which the novices make sense of these expectations is known to depend, to a large extent, on the personal 'perspectives' that they develop towards their practice. ${ }^{48}$ These are the actions and the nature to act that operate when novices deal with a problematic situation, as drawn by their prior experiences, knowledge and beliefs. $^{48}$

Student nurses exhibited a philosophy of the profession that focused on performance and the outcomes of caring rather than on the processes of caring and curing the patient. ${ }^{48}$ Novices focus on their successful or unsuccessful performance and lacked explanation of their rationale for action as well as the implications of their performance. ${ }^{48}$ 
The students also tended to focus on pedagogical and subject matter aspects of the profession, disregarding aspects of their work that take account of personal, systemic and organizational influences. ${ }^{48}$ Orland-Barak and Wilhelem ${ }^{48}$ also found that the novices' reasoning is characterized by rigidness, their need to adopt a single, homogeneous perspective to a problem, and a lack of sensitivity for how different contexts call for different kinds of solutions.

Botti and Reeve ${ }^{49}$ examined the clinical decision making skills of nursing students. They found that the key difference between novice and expert students to be novices are in the process of acquiring domain specific knowledge and have limited experience with nursing-related problems. ${ }^{49}$ Novices are more reliant on their general problem-solving ability in making clinical judgments and that there are transitions during the acquisition of expertise when general ability and knowledge function are independent of each other. ${ }^{49}$

Novices are thought to have backward reasoning with decision-making because novices tend to deal with largely unfamiliar problems and have limited related knowledge. ${ }^{49}$ Novices tend to ignore disconfirming cues or reinterpret them to be consistent with the most likely diagnosis, and they were less likely to recognize the implications of disconfirming information than the experienced nurse. ${ }^{49}$ They also tend to try to confirm their hypotheses by collecting more information rather than to disconfirm their hypotheses by selecting disconfirming cues. ${ }^{49}$

ACI training workshop: The training workshop that an ATC must take to become an ACI was developed to meet the needs of each individual institution. According to the Standards for the Accreditation of Entry-Level Athletic Training Education Programs ${ }^{4}$ the 
following content area must be covered in the ACI training workshop. Table 2 list and describes the content area that includes learning styles and instructional skills, review of the Athletic Training Educational Competencies, evaluation of student performance and feedback, instructional skills of supervision, mentoring, and administration, program/institution-specific policies, procedures, and clinical education requirements, legal and ethical behaviors, communication skills, appropriate interpersonal relationships, and appropriate clinical skills and knowledge.

Table B2. Content Area and Description of Content Area for an ACI Training Workshop ${ }^{4,50}$

Content Area Description

Learning styles and instructional skills Increase the awareness of the ACI to be more aware of the various types of learners, and therefore include multiple types of stimuli to reach each type of learner. It is also important for the ACI to determine what kind of learners each of their ATSs are and then try to use that method of teaching to reach the ATS.

Review of the Athletic Training Educational Competencies

Evaluation of student performance and feedback

Instructional skills of supervision, mentoring, and administration
Encompasses the various types of competencies and proficiencies that are needed to prepare the ATS to be an entry-level certified athletic trainer. This also makes the ACI aware of the content upon which he or she will be evaluating the ATS.

To prepare the ATS to be an entry-level athletic trainer, evaluation of performance, subtleties, and skills are an essential part of the learning process; Evaluation provides the ATS with positive feedback in which will assist them in the mastery of the competencies or proficiencies.

- Supervision-- this is the responsibility of the ACI to be willingly available to the ATS to ask questions and provide feedback. Also for the ACI to encourage the ATS to ask for help, develop autonomy, and work within the ATS's knowledge and level of experience. This also allows the ACI to watch the ATS's performance. 
- Mentoring - this is the responsibility of the ACI to develop a relationship between the ACI and the ATS. Mentoring consists of a relationship involving several different domains, such as role modeling, teaching, nurturing, advocacy, and socialization. ${ }^{19}$

- Administration - this is the responsibility of the ACI to perform routine administrative tasks associated with athletic training clinical education. The ACI needs to make time to complete administrative responsibilities connected with clinical education such as, completing and discussing clinical evaluation forms with the ATS, evaluating skill performance, and documenting clinical progression in completing the required clinical proficiencies. Also based on a student's level of experience, delegate different clinical tasks to the student. ${ }^{6}$

Program/institution-specific policies, procedures, and clinical education requirements

Legal and ethical behaviors

Communication skills

Appropriate interpersonal relationships

Appropriate clinical skills and knowledge
To familiarize the ACI with the institution's policies and procedures as well as the clinical education program.

Responsibility of the ACI to be a good role model for the ATS by following the NATA Code of Ethics set forth by the NATA as well as be in good standing with the NATA and the BOC.

Responsibility of the ACI to have active listening skills, adapt to the variety of learning styles the ATS might possess, provide positive feedback, and clarify explanations of any expectations or problems.

Responsibility of the ACI to maintain a professional relationship with the ATS as well as to serve as a role model.

Responsibility of the ACI to demonstrate appropriate clinical competence in the twelve athletic training domains. 
Since the publication of the 2005 Standards, ${ }^{4}$ there is no longer a set period of time in which the ACI training workshop must last. The last criteria that an ATC must meet to be an ACI is that he/ she must be trained/re-trained by the institution's CIE at least once every three years.

Summary

Athletic training education formally began in 1959 with the developed of the first athletic training curriculum model. The accrediting body of the profession of athletic training has undergone multiple accrediting administrations and is back "in-house.” As well as the didactic athletic training education undergoing change over the years, clinical education has undergone many changes as well. Clinical education is an important aspect of any athletic trainer's education. Today’s clinical education now involves the student being proficient and mastering various competencies and proficiencies during their entire clinical experience. When an ATS has graduated from an institution with a degree in athletic training, they can pursue their education in the field of athletic training by obtaining a master's degree at a NATA accredited post-professional graduate athletic training program or a degree in another field. Once the ATS meets all the necessary requirements to sit for the certification examination and pass the examination, they obtain the credentials of a certified athletic trainer. Once they have been a certified athletic trainer for a year and have at least one year of clinical experience as an ATC, they can become an ACI. ACIs are responsible for the evaluation of the ATS's competencies and proficiencies and the ATS's clinical experience. The training of an ACI is very basic, and it is unknown if the one workshop proves to be sufficient to prepare the novice graduate assistant ATC to be a confident ACI. 


\section{APPENDIX C}

\section{ADDITIONAL METHODS}

\section{Table C1. Initial E-mail to Undergraduate Program Director’s}

Dear Undergraduate Program Director:

Hello, my name is Christopher Pircher. I am a graduate student at West Virginia University, as well as a Graduate Assistant certified athletic trainer. In order to fulfill the requirements of a master's thesis and complete my Masters of Science in Athletic Training, I am inviting you to participate in a research study entitled "Perceived Preparedness of Graduate Assistant Novice Approved Clinical Instructors for Supervision of Undergraduate Athletic Training Students.” I am conducting this research with the Primary Investigator Michelle A. Sandrey, PhD, ATC. She is also affiliated with West Virginia University.

The purpose of this study is to gather novice graduate assistant approved clinical instructor's perceived preparedness in the supervision of undergraduate athletic training students during the approved clinical instructors first year of clinical instruction. Your institution has been selected due to having been CAATE accredited for a period of five years or longer.

The design behind this research is based on a questionnaire developed by the co-primary investigator. If you are willing to have your institution participate in the research study, then you will receive a cover letter via e-mail which will have a link to the questionnaire. You are then asked to send the cover letter to all of your graduate assistant approved clinical instructors for them to complete. The questionnaire consists of demographic and content material. Each question is based on the Likert scale and yes / no. The questionnaire should only take a few minutes to complete. Not all of the questions have to be answered. Your institutions novice graduate assistant approved clinical instructors may withdraw with no penalty any time throughout the research study. Once the questionnaires are completed the participant is asked to click "submit this form."

Your involvement in this survey will be kept completely anonymous for the duration of the study. I will not ask you to include your name on any of the questions nor will I present any information at any time that could allow for individual participants to be identified. You may withdrawal with no penalty any time throughout the study.

Your participation in this research is extremely important and will help the profession of athletic training better the individuals that are supervising the future of our profession.

If you are willing to participate in this research study, please submit 1) whether you have novice graduate assistant ACIs supervising your institutions ATSs and 2) the number of graduate assistant ACIs your institution has supervising ATSs. Thank you in advance for your time.

Best Regards,

Christopher M. Pircher, ATC

cpircher@mix.wvu.edu

*WVU IRB acknowledgement of this study 


\title{
WhestVirginiaUniversity
}

\author{
School of Physical Education
}

February 28, 2008

Dear Graduate Assistant Approved Clinical Instructor: c/o Undergraduate Program Director:

Thank you for agreeing to participate in a research study being conducted by the primary investigator (PI) Michelle A. Sandrey PhD, ATC and Co-PI Christopher Pircher ATC, a Graduate Athletic Training Student. Both are affiliated with West Virginia University. The main purpose of this study is to determine if novice graduate assistant approved clinical instructors are prepared in the supervision of undergraduate athletic training students in the clinical education setting. This thesis is being completed to partially fulfill requirements for the completion of a Master of Science Degree in Athletic Training at West Virginia University.

The following is a 47-item questionnaire on demographic and content material. This questionnaire is for your institutions current novice graduate assistant approved clinical instructors to complete. You do not have to answer all the questions. You may withdraw from the study at any time with no penalty. Your status as a graduate assistant will not be jeopardized if you do not complete the questionnaire. The questionnaire should only take ten minute to complete. Please go to the following website to take the survey: http://simpleforms.script.wvu.edu/sf/GradACIQuestionnaire

Your involvement in this survey will be kept completely anonymous for the duration of the study. You will not be asked to include your name on any of the questions nor will I present any information at any time that could allow for individual participants to be identified. You may withdrawal with no penalty any time throughout the study.

I respectfully request that you participate in this study, as it could be very beneficial for clinical athletic training education and the future of the profession. I would like to thank you very much for your time. If you should have any questions regarding this letter, questionnaire, or study in general, please feel free to contact me Christopher Pircher ATC at (210)535-1768 or cpircher@mix.wvu.edu or Dr. Michelle A. Sandrey at (304)293-3295 ext 5220 or msandrey@mail.wvu.edu.

Thank you very much, in advance, for your participation in this study.

Sincerely,

Christopher Pircher, ATC

*WVU IRB acknowledgement of this study is on file

Phone: 304-293-3295

Athletic Coaching Education - Athletic Training • Sports Management Sport and Exercise Psychology • Physical Education Teacher Education

PO Box 6116

Fax: $\quad 304-293-4641$

Morgantown, WV 26506-6116

Equal Opportunity/Affirmative Action Institution 


\title{
WestVirginiaUniversity
}

\author{
School of Physical Education
}

March 12, 2008

Dear Graduate Assistant Approved Clinical Instructor: c/o Undergraduate Program Director:

Thank you for agreeing to participate in a research study being conducted by the primary investigator (PI) Michelle A. Sandrey PhD, ATC and Co-PI Christopher Pircher ATC, a Graduate Athletic Training Student. Both are affiliated with West Virginia University. The main purpose of this study is to determine if novice graduate assistant approved clinical instructors are prepared in the supervision of undergraduate athletic training students in the clinical education setting. This thesis is being completed to partially fulfill requirements for the completion of a Master of Science Degree in Athletic Training at West Virginia University.

The following is a 47-item questionnaire on demographic and in content material. This questionnaire is for your institutions current novice graduate assistant approved clinical instructors to complete. You do not have to answer all the questions. You may withdraw from the study at any time with no penalty. Your status as a graduate assistant will not be jeopardized if you do not complete the questionnaire. The questionnaire should only take ten minute to complete. Please go to the following website to take the survey:

http://simpleforms.script.wvu.edu/sf/GradACIQuestionnaire

Your involvement in this survey will be kept completely anonymous for the duration of the study. I will not ask you to include your name on any of the questions nor will I present any information at any time that could allow for individual participants to be identified.

I respectfully request that you participate in this study, as it could be very beneficial for clinical athletic training education and the future of the profession. I would like to thank you very much for your time. If you should have any questions regarding this letter, questionnaire, or study in general, please feel free to contact me Christopher Pircher ATC at (210)535-1768 or cpircher@mix.wvu.edu or Dr. Michelle A. Sandrey at (304)293-3295 ext 5220 or msandrey@mail.wvu.edu. This is a follow-up letter to let you know there is still time to fill out the questionnaire. Thank you as this is just a reminder letter.

Thank you in advance for your participation in this study.

Sincerely,

Christopher Pircher, ATC

*WVU IRB acknowledgement of this study is on file

Athletic Coaching Education - Athletic Training • Sports Management Sport and Exercise Psychology • Physical Education Teacher Education

Phone: 304-293-3295

PO Box 6116

Fax: $\quad 304-293-4641$

Morgantown, WV 26506-6116

Equal Opportunity/Affirmative Action Institution 
Thank you for parcipitating in this study that will help identify if graduate assistant approved clinical instructors are prepared to supervise athletic training students. Please answer the following questions honestly and to the best of your ability. At the conclusion of the survey, you will be asked to click the "Submit this Form" button. By clicking on "Submit this Form", you are indicating your voluntary participation in this study and are permitting your results to be used. Your identity is confidential. This study has been approved by the Institutional Review Board at West Virginia University.

Are you a graduate student?
C Yes
C No

Are you an Approved Clincial Instructor (ACI)?
C Yes
C No

How many years have you been an ACI?

C Less than one year

C One year

C One to two years

C Two years

C More than two years

How many years have you been a certified athletic trainer (ATC)?

C Less than one year

C One year

C One to two years

C Two years

C More than two years

What is your current clinical setting? (the setting in which you spend the most time performing clinical athletic training duties)
C College / University
C High School
C Clinic/Outreach
C Industrial
C Other 
How many athletic training students (ATS) are you currently supervising?
C 0
C 1 - 2
C $3-4$
C $5-6$
C $6-7$
C 8

Are you in a clinical setting in which there are other ACIs supervising other ATSs?

C Yes

C No

In your current clinical setting, are you directly supervised on a daily basis by a full-time staff ATC.
C Yes
No

Were you supervised by a graduate student ACI during your own undergraduate experience?
C Yes
C No

Learning Styles

During my ACI training workshop a variety of ATS learning styles were presented?

Strongly Agree

Agree $\mathrm{C}$

Neutral[

Disagree

Strongly Disagree

The information that I received on learning styles during the ACI training workshop prepared me to identify the different ATS learning styles utilized.

Strongly Agree $\mathrm{C}$

Agree $\mathrm{C}$

Neutral [

Disagree $\mathrm{C}$

Strongly Disagree 
I am confident that my clinical instruction is tailored to fit the learning style of the ATS.

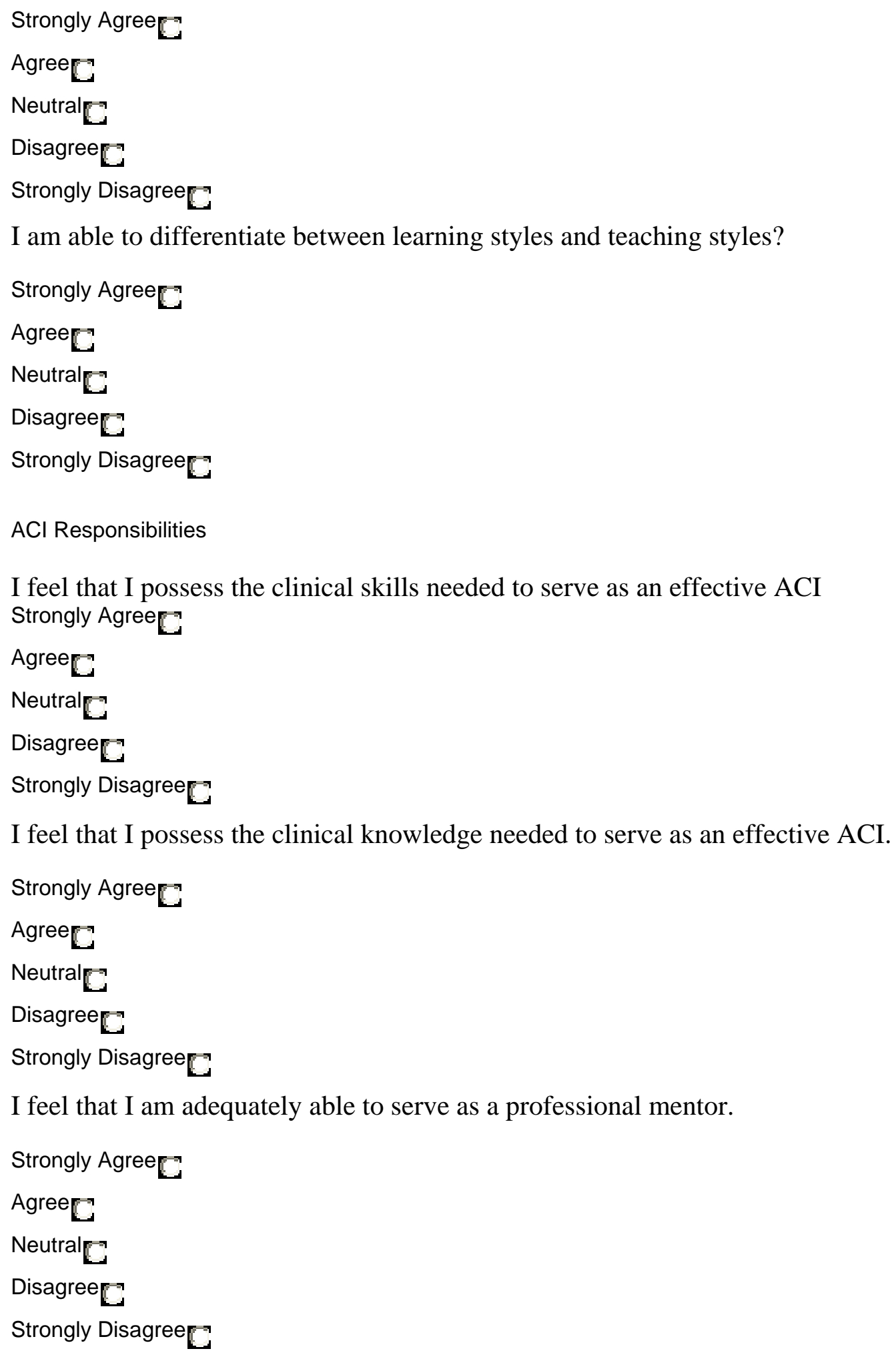


I feel confident in demonstrating legal and ethical behaviors.

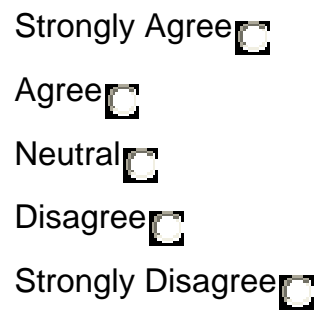

I feel that if a situation arose involving an ATS and improper legal or ethical behavior in my clinical setting, I would be prepared to properly handle the situation.

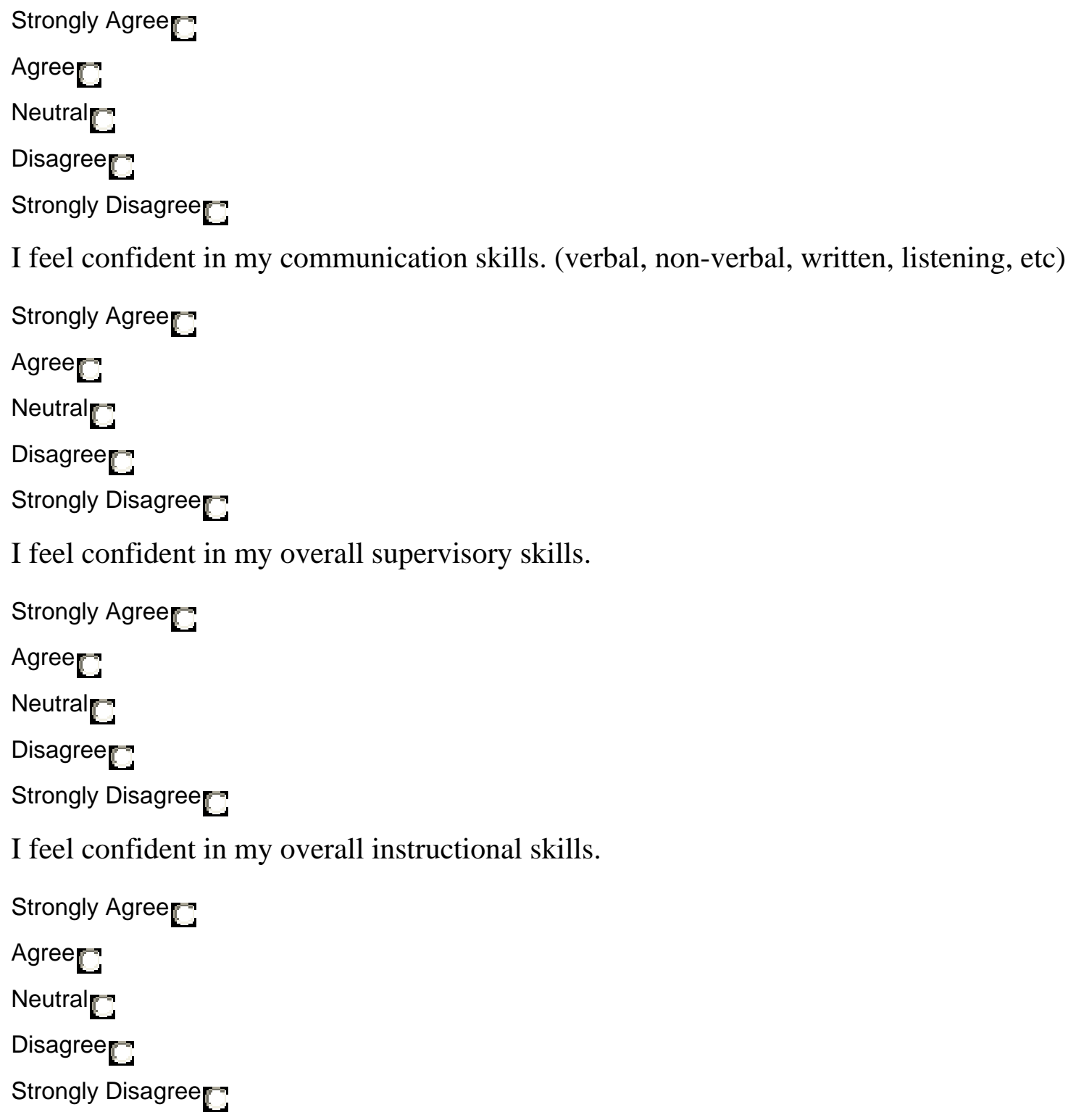


I feel confident in my overall evaluation skills.

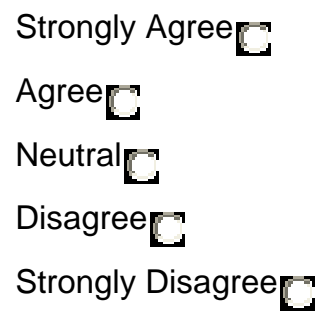

I feel that if a situation arose involving an ATS and an improper / compromising interpersonal relationship in my clinical setting, I would be prepared to properly handle the situation.

Strongly Agree $\mathrm{C}$

Agree $\mathrm{C}$

Neutral[ [

Disagree $\mathrm{C}$

Strongly Disagree

I feel that I have a good understanding of my institution's athletic training policies and procedures to serve as an ACI.

Strongly Agree $\mathrm{C}$

Agree $\mathrm{C}$

Neutral [C

Disagree $\mathrm{C}$

Strongly Disagree [

I feel confident in performing a constructive self-evaluation of my skills and performance as an ACI.

Strongly Agree $\mathbf{C}$

Agree $\mathbf{C}$

Neutral $\mathbf{C}$

Disagree $\mathrm{C}$

Strongly Disagree

I feel confident in the use of my institution's evaluation tools.

Strongly Agree $\mathbf{C}$

Agree $\mathbf{C}$

Neutral $\mathrm{C}$

Disagree $\mathbf{C}$

Strongly Disagree 
Evaluation and Feedback of Student Performance

I felt prepared to evaluate my ATS's first clinical proficiency.

Strongly Agree $\mathrm{C}$

Agree

Neutral[

Disagree $\mathrm{C}$

Strongly Disagree

I feel confident in evaluating a ATS's clinical knowledge.

Strongly Agree

Agree $\mathrm{C}$

Neutral[ $\mathrm{C}$

Disagree $\mathrm{C}$

Strongly Disagree

I feel confident in evaluating an ATS's clinical skills.

Strongly Agree

Agree $\mathrm{C}$

Neutral[

Disagree

Strongly Disagree

I feel confident in evaluating an ATS's professional behavior.

Strongly Agree

Agree $\mathrm{C}$

Neutral $\mathrm{C}$

Disagree

Strongly Disagree $\mathrm{C}$

I feel confident in evaluating an ATS's clinical decesion making.

Strongly Agree

Agree $\mathrm{C}$

Neutral

Disagree

Strongly Disagree 
I feel prepared to give effective positive feedback to the ATS.

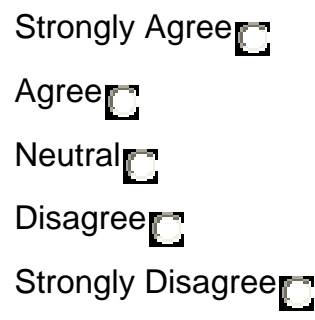

I feel prepared to give effective constructive feedback to the ATS to improve their performance.

Strongly Agree

Agree $\mathbf{C}$

Neutral $\mathbf{C}$

Disagree $\mathbb{C}$

Strongly Disagree

I feel confident in providing students feedback on clinical knowledge.

Strongly Agree $\mathbf{C}$

Agree $\mathbf{C}$

Neutral $\mathbf{C}$

Disagree $\mathbb{C}$

Strongly Disagree

I feel confident in providing students feedback on clinical skills.

Strongly Agree

Agree $\mathbf{C}$

Neutral $\mathbf{C}$

Disagree $\mathbf{C}$

Strongly Disagree $\mathbf{C}$

I feel confident in providing students feedback on professional behaviors.

Strongly Agree $\mathbf{C}$

Agree $\mathbf{C}$

Neutral $\mathbf{C}$

Disagree $\mathbf{C}$

Strongly Disagree $\mathbf{C}$ 
I feel confident in providing students feedback on clinical decision making.

Strongly Agree $\mathrm{C}$

Agree $\mathrm{C}$

Neutral[

Disagree $\mathrm{C}$

Strongly Disagree

Which of the following do you feel the most confident in evaluating?

C Clinical knowledge

Clinical skills

C Professional behavior

C Clinical decision making

Which of the following do you feel the most confident in providing feedback?

C Clinical knowledge

C Clinical skills

C Professional behavior

C Clinical decision making

ACI Preparation

I am aware of the characteristics of an effective clinical instructor.

Strongly Agree

Agree $\mathrm{C}$

Neutral[ [

Disagree $\mathrm{C}$

Strongly Disagree

I am able utilize the various characteristics of an effective clinical instructor to make me a better ACI.

Strongly Agree

Agree $\mathrm{C}$

Neutral [

Disagree $\mathrm{C}$

Strongly Disagree 
I understand the "Teaching / Learning Over Time” concept.

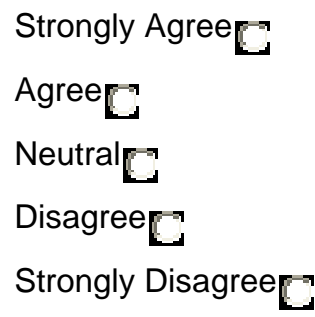

Overall, I feel that my institution's ACI training workshop prepared me to be an effective ACI in my first year.

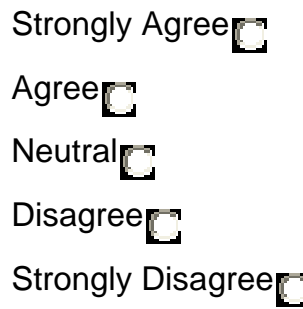

Overall, I feel that my institution's ACI training workshop was beneficial to me as an ACI.

Strongly Agree[

Agree $\mathrm{C}$

Neutral[

Disagree [

Strongly Disagree $\mathrm{C}$

In my opinion, an ATC with one year of clinical experience and completion of an ACI training workshop should serve as an ACI.

Strongly Agree

Agree[

Neutral[

Disagree [

Strongly Disagree 
In retrospect, what do you feel was the greatest challenges of being a first year $\mathrm{ACl}$ ? (Please rank your top 3, 1 = the item in which you are most comfortable. Not all answers will have a response.)

Experienced no challenges as an graduate assistant $\mathrm{ACl}$

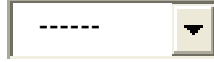

Understanding institutional policies / procedures

- - -

Controlling the learning environment

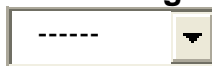

Time Constraints

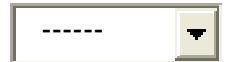

Communication

|---

Providing feedback on clinical knowledge

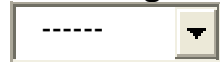

Providing feedback on clinical skills

--- -

Providing feedback on professional behaviors

-----

Evaluation of clinical knowledge

\begin{tabular}{ll|}
\hline$----\quad *$ \\
\hline
\end{tabular}

Evaluation of clinical skills

\begin{tabular}{|l|}
\hline$----\quad-$ \\
\hline
\end{tabular}

Evaluation of professional behaviors

|--- $\quad$ -

Evaluation of clinical proficiencies

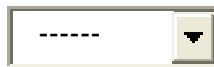

Overall, how would you rate your performance in your first year serving as an ACI. (zero being the worst performance and ten being the best performance)
C 0
C 1
C 2
C 3
C 4
C 5
C 6
C 7
C 8
C 9
C 10 
Please use this space to provide any additional comments.

Thank you for taking the time to fill out the questionnaire on graduate assistant $\mathrm{ACI}$ preparedness. If you have any questions or would like to contact me regarding my results feel free to email me at cpircher@mix.wvu.edu .

Christopher M. Pircher, ATC

Graduate Assistant Athletic Trainer

West Virginia University 


\section{APPENDIX D}

\section{ADDITIONAL RESULTS}

Table D1. Demographic Characteristics of Questionnaire Participants ( $\mathrm{n}=33$ )

\begin{tabular}{|c|c|c|}
\hline & Frequency & Percent \\
\hline Graduate Student & 33 & $100.0 \%$ \\
\hline ACI & 33 & $100.0 \%$ \\
\hline \multicolumn{3}{|l|}{ Years as an ACI } \\
\hline Less than 1 year & 16 & $48.5 \%$ \\
\hline 1 year & 09 & $27.3 \%$ \\
\hline $1-2$ year & 08 & $24.2 \%$ \\
\hline 2 year & 00 & $00.0 \%$ \\
\hline \multicolumn{3}{|l|}{ Years as an ATC } \\
\hline 1 year & 01 & $3.0 \%$ \\
\hline $1-2$ years & 12 & $36.4 \%$ \\
\hline 2 years & 12 & $36.4 \%$ \\
\hline More than 2 years & 08 & $24.2 \%$ \\
\hline \multicolumn{3}{|l|}{ Current Clinical Setting } \\
\hline College / University & 24 & $72.7 \%$ \\
\hline High School & 09 & $27.3 \%$ \\
\hline \multicolumn{3}{|l|}{ Number of ATSs supervised } \\
\hline $1-2$ & 13 & $39.3 \%$ \\
\hline $3-4$ & 15 & $45.5 \%$ \\
\hline $5-6$ & 03 & $9.1 \%$ \\
\hline 8 & 02 & $6.1 \%$ \\
\hline \multicolumn{3}{|c|}{ Other ACIs in your clinical setting } \\
\hline Yes & 23 & $69.7 \%$ \\
\hline No & 10 & $30.3 \%$ \\
\hline \multicolumn{3}{|c|}{ Directly Supervised by staff ATC } \\
\hline Yes & 10 & $30.3 \%$ \\
\hline No & 23 & $69.7 \%$ \\
\hline \multicolumn{3}{|c|}{ Supervised by GA ACI during own UG experience } \\
\hline Yes & 18 & $54.5 \%$ \\
\hline No & 15 & $45.5 \%$ \\
\hline
\end{tabular}

Key: ACI = Approved Clinical Instructor; ATC $=$ Certified Athletic Trainer; ATS $=$ Athletic Training Student; GA= Graduate Assistant; UG= Undergraduate 


\begin{tabular}{lll}
\hline & Frequency & Percent \\
\hline Various learning style presented during ACI & & \\
training workshop & 17 & $51.5 \%$ \\
$\quad$ Strongly Agree & 12 & $36.4 \%$ \\
Agree & 03 & $9.1 \%$ \\
Neutral & 00 & $0.00 \%$ \\
$\quad$ Disagree & 01 & $3.0 \%$ \\
$\quad$ Strongly Disagree & & \\
Information on ATS learning styles prepared & 10 & $30.3 \%$ \\
ACI to identify different styles utilized & 16 & $48.5 \%$ \\
$\quad$ Strongly Agree & 04 & $12.1 \%$ \\
Agree & 02 & $6.1 \%$ \\
Neutral & 01 & $3.0 \%$ \\
Disagree & & \\
Strongly Disagree & & \\
Confident that ACI clinical instruction was & 07 & $21.2 \%$ \\
tailored to fit learning style of ATS & 18 & $54.5 \%$ \\
$\quad$ Strongly Agree & 06 & $18.2 \%$ \\
Agree & 02 & $6.1 \%$ \\
Neutral & 00 & $00.0 \%$ \\
Disagree & & \\
$\quad$ Strongly Disagree & & $24.2 \%$ \\
ACI able to differentiate between learning style & 08 & $51.5 \%$ \\
and teaching style & 17 & $21.2 \%$ \\
$\quad$ Strongly Agree & 07 & $3.1 \%$ \\
Agree & 01 & $00.0 \%$ \\
$\quad$ Neutral & 00 & \\
Disagree &
\end{tabular}

Key: ACI = Approved Clinical Instructor; ATS = Athletic Training Student 


\begin{tabular}{llc}
\hline & Frequency & Percent \\
\hline $\begin{array}{l}\text { Possess the clinical skills needed to serve as } \\
\text { an effective ACI }\end{array}$ & & \\
$\quad \begin{array}{l}\text { Strongly Agree } \\
\text { Agree }\end{array}$ & 11 & $33.3 \%$ \\
$\begin{array}{l}\text { Possess the clinical knowledge needed to serve } \\
\text { as an effective ACI }\end{array}$ & \\
$\quad$ Strongly Agree & 09 & \\
$\quad$ Agree & 24 & $72.7 \%$ \\
Adequately able to serve as a professional mentor & 15 & $45.5 \%$ \\
$\quad$ Strongly Agree & 17 & $51.5 \%$ \\
$\quad$ Agree & 01 & $3.0 \%$ \\
$\quad$ Neutral & & \\
Confident in demonstrating legal and ethical & & $42.4 \%$ \\
behaviors & 14 & $51.5 \%$ \\
$\quad$ Strongly Agree & 17 & $6.1 \%$
\end{tabular}

If a situation arose involving an ATS and improper legal or ethical behavior in their clinical setting, the ACI was prepared to properly handle the situation

Strongly Agree

$\begin{array}{ll}11 & 33.3 \% \\ 16 & 48.5 \% \\ 05 & 15.2 \% \\ & \\ 12 & 36.4 \% \\ 20 & 60.6 \% \\ 01 & 3.0 \% \\ & \\ 10 & 30.3 \% \\ 21 & 63.6 \% \\ 02 & 6.1 \% \\ & \\ 08 & 24.2 \% \\ 24 & 72.7 \% \\ 01 & 3.0 \% \\ & \\ 11 & 33.3 \% \\ 19 & 57.6 \% \\ 03 & 9.1 \%\end{array}$


If a situation arose involving an ATS and an improper / compromising interpersonal relationship in the ACI clinical setting, the ACI felt prepared to properly handle the situation

Strongly Agree

Agree

Neutral

ACI had a good understanding of institution's athletic training policies and procedures to serve as an ACI.

Strongly Agree $\quad 09$

$27.3 \%$

Agree

Neutral

$6.1 \%$

Disagree

01

$3.0 \%$

Confident in using institutions evaluation tools

Strongly Agree

$21.2 \%$

Agree

Neutral

04

12.1

Disagree

02

$6.1 \%$

Confident in performing a constructive self-evaluation

of the ACIs' skills and performance as an ACI

Strongly Agree

Agree

Neutral

04

$12.1 \%$

Key: ACI = Approved Clinical Instructor; ATS $=$ Athletic Training Student 
Table D4. Evaluation and Feedback of Student Performance ( $\mathrm{n}=33)$

Table D4. Evaluation and Feedback of Student Petformance (n

ACI felt prepared to evaluate ATS's first clinical proficiency

Strongly Agree

13

$39.4 \%$

Agree

13

Neutral

03

$39.4 \%$

Disagree

04

$9.1 \%$

$12.1 \%$

Confidence in evaluating an ATS's clinical

knowledge

Strongly Agree

16

$48.5 \%$

Agree

17

$51.5 \%$

Confidence in evaluating an ATS's clinical

skills

Strongly Agree

14

$42.4 \%$

Agree

19

$57.6 \%$

Confidence in evaluating an ATS's professional

behavior

Strongly Agree

15

$45.5 \%$

Agree

14

$42.4 \%$

Neutral

03

$9.1 \%$

Confidence in evaluating an ATS's clinical decision making

Strongly Agree

11

$33.3 \%$

Agree

19

$57.6 \%$

Neutral

03

9.1

Prepared to give effective positive feedback to the ATS

Strongly Agree

16

$48.5 \%$

Agree

15

$45.5 \%$

Neutral

01

$3.0 \%$

Disagree

01

$3.0 \%$

Prepared to give constructive feedback to the ATS to improve his or her performance

Strongly Agree

15

$45.5 \%$

Agree

17

$51.5 \%$

Neutral

01

$3.0 \%$

Confidence in providing students feedback on clinical knowledge

Strongly Agree

16

$48.5 \%$

Agree

17

$51.5 \%$

Confidence in providing students feedback on clinical skills

Strongly Agree

15

$45.5 \%$

Agree

17

$51.5 \%$

Neutral

01

$3.0 \%$ 
Confidence in providing students feedback on professional behaviors

Strongly Agree

$45.5 \%$

Agree

15

$45.5 \%$

Neutral

03

$9.1 \%$

Confidence in providing students feedback on

clinical decision making

Strongly Agree

$48.5 \%$

Agree

15

$45.5 \%$

Neutral

02

$6.1 \%$

Which of the following did the ACI feel the most confident in evaluating

Clinical knowledge

$12.1 \%$

Clinical skills

Clinical decision making

07

$21.2 \%$

Professional behavior

02

$6.1 \%$

Which of the following did the ACI feel the most

confident in providing feedback

Clinical knowledge

Clinical skills

Clinical decision making

04

$12.1 \%$

Professional behavior

03

$9.1 \%$

Key: ACI = Approved Clinical Instructor; ATS = Athletic Training Student 


\begin{tabular}{|c|c|c|}
\hline & Frequency & Percent \\
\hline \multicolumn{3}{|c|}{$\begin{array}{l}\text { Aware of the characteristics of an effective } \\
\text { clinical instructor }\end{array}$} \\
\hline Strongly Agree & 10 & $30.3 \%$ \\
\hline Agree & 19 & $57.6 \%$ \\
\hline Neutral & 02 & $6.1 \%$ \\
\hline Disagree & 02 & $6.1 \%$ \\
\hline \multicolumn{3}{|c|}{$\begin{array}{l}\text { Utilizes characteristics of an effective clinical } \\
\text { instructor to make the ACI an better ACI }\end{array}$} \\
\hline Strongly Agree & 05 & $15.2 \%$ \\
\hline Agree & 21 & $63.3 \%$ \\
\hline Neutral & 06 & $18.2 \%$ \\
\hline Disagree & 01 & $3.0 \%$ \\
\hline \multicolumn{3}{|c|}{$\begin{array}{l}\text { The ACI understood the "Teaching Over Time" } \\
\text { concept }\end{array}$} \\
\hline Strongly Agree & 16 & $48.5 \%$ \\
\hline Agree & 10 & $30.3 \%$ \\
\hline Neutral & 05 & $15.2 \%$ \\
\hline \multirow{2}{*}{\multicolumn{3}{|c|}{$\begin{array}{l}\text { Overall, the ACI felt that their institutions ACI } \\
\text { training workshop prepared them to be an } \\
\text { effective ACI in their first year }\end{array}$}} \\
\hline & & \\
\hline Strongly Agree & 08 & $24.2 \%$ \\
\hline Agree & 18 & $54.5 \%$ \\
\hline Neutral & 03 & $9.1 \%$ \\
\hline Disagree & 03 & $9.1 \%$ \\
\hline Strongly Disagree & 01 & $3.0 \%$ \\
\hline \multicolumn{3}{|c|}{$\begin{array}{l}\text { Overall the ACI felt that their institution's ACI } \\
\text { training workshop was beneficial to them as an } \\
\text { ACI }\end{array}$} \\
\hline Strongly Agree & 11 & $33.3 \%$ \\
\hline Agree & 14 & $42.4 \%$ \\
\hline Neutral & 05 & $15.2 \%$ \\
\hline Disagree & 03 & $9.1 \%$ \\
\hline \multicolumn{3}{|c|}{$\begin{array}{l}\text { In the ACI opinion, an ATC with one year of } \\
\text { experience and completion of an ACI training } \\
\text { workshop could serve as an ACI }\end{array}$} \\
\hline Strongly Agree & 13 & $39.4 \%$ \\
\hline Agree & 16 & $48.5 \%$ \\
\hline Neutral & 03 & $9.1 \%$ \\
\hline Disagree & 01 & $3.0 \%$ \\
\hline
\end{tabular}

Key: ACI = Approved Clinical Instructor; ATC $=$ Certified Athletic Trainer 
Figure 1. Approved Clinical Instructor Perceived Greatest Challenges $(n=28)$

$\square$ First Choice $\square$ Second Choice $\square$ Third Choice

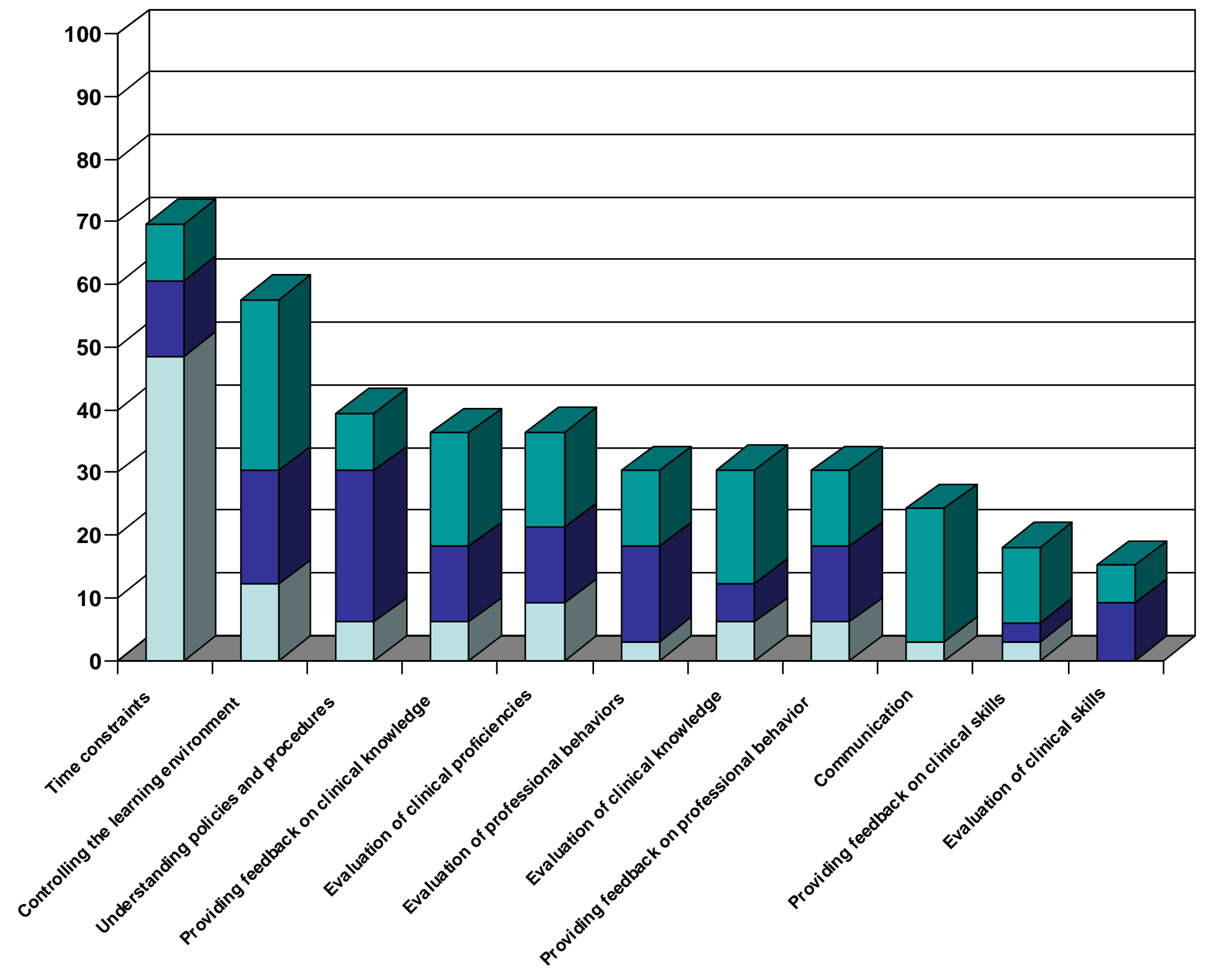




\section{APPENDIX E \\ RECOMMENDATIONS FOR FUTURE RESEARCH}

1. A recommendation for future research is to repeat this study using a larger sample size.

2. Another recommendation for future research is to ask a question asking the novice ACIs in which area are they the least confident in the evaluation and in providing feedback.

3. Another recommendation is to examine the responses of different experience levels of the ACIs (ie novice compared to expert).

4. Another recommendation for future research is to use programs that have been accredited for a different amount of time other than five years.

5. Follow-up the questionnaire with a interview to bring in more in depth information in regard to first year graduate assistant ACI experience. 


\section{ADDITIONAL REFERENCES}

18. Delforge GD, Behnke RS. The history and evolution of athletic training education in the United States. J Athl Train. 1999;34(1):53-61.

19. Panseri ML. An Exploration of Mentoring in Athletic Training Clinical Education: Established a Preliminary Model Based on the Grounded Theory [master’s thesis]. Morgantown, WV: West Virginia University; 2005.

20. Denhup SA. Behavioral Analysis in the Athletic Training Clinical Learning Environment [master's thesis]. Morgantown, WV: West Virginia University; 2003.

21. Mensch JM. Are we asking too much from athletic training students in the clinical setting? Athl Ther Today. 2006;11(2):30-31.

22. Nasypansy A. Survey of Athletic Training Clinical Education: Perception from the Field [disserertation]. Morgantown, WV: West Virginia University; 2005.

23. Miller MG, Berry DC. An assessment of athletic training students' clinicalplacement hours. J Athl Train. 2002;37(4 Supplement):S-229-S-235.

24. Board of Certification for the Athletic Trainer. Available at: http://www.bocatc.org/index.php?option=com_content\&task=view\&id=100\&Ite mid=105. Accessed July 10, 2007.

25. Heinerichs S, Curtis N. Instructional strategy for clinical education: the 3-2-1 technique. Athl Ther Today. 2006;11(4):52-53.

26. Pitney WA, Ehlers GG. A grounded theory study of the mentoring process involved with undergraduate athletic training students. J Athl Train. 2004;39(4):344-351.

27. Weidner TG, Pipkin J. Clinical supervision of athletic training students at colleges and universities need improvement. J Athl Train. 2002;37(4 Supplement):S-241-S-247.

28. Kelly SP. The exemplary clinical instructor: a qualitative case study. J Phys Ther Edu. 2007;21(1):63-69.

29. Weidner TG, Popp JK. Peer-assisted learning and orthopaedic evaluation psychomotor skills. J Athl Train. 2007;42(1):113-119.

30. Berry DC, Miller MG, Berry LM. Effects of clinical field-experience setting on athletic training students' perceived percentage of time spent on active learning. $J$ Athl Train. 2004;39(2):176-184. 
31. Wojciechowski M. Clinical instructor education and credentialing program: a decade later. PT: Magazine of Physical Therapy. Feb2007;15(2):70-4.

32. Hartland W, Londoner CA. Perceived importance of clinical teaching characteristics for nurse anesthesia clinical faculty. JAANA. 1997;65(6):547-551.

33. Geisler PR. Multiculturalism and athletic training education: implications for educational and professional progress. J Athl Train. 2003;38(2):141-151.

34. Amato HK, Konin JG, Brader H. A model for learning over time: the big picture. J Athl Train. 2002;37(2 Supplement):S-236-S-240.

35. Konin JG, Amato HK, Brader H. Incorporating the renne test into the learningover-time model. Athl Ther Today. 2002;7(5):12-17.

36. Wilkerson GB, Colston MA, Bogdanowicz BT. Distinctions between athletic training education programs at the undergraduate and graduate levels. Ath Train Edu J. 2006;1(Apr-Dec):38-40.

37. Mathies AL, Denegar CR, Arnhold RW. Changes in athletic training education as a result of changing from NATA-PEC to CAAHEP. J Athl Train. 1995;30(2):129-132.

38. Peer KS, Rakich JS. Accreditation and continuous quality improvement in athletic training education. J Athl Train. 2000;35(2):188-193.

39. Athletic Training Educational Competencies. 4th edition. 2006.

40. National Athletic Trainers' Association Board of Certification. Role Delineation Study. 5th ed. Omaha, Neb: NATABOC, Inc; 2004.

41. Seegmiller JG. Perceptions of quality for graduate athletic training education. $J$ Athl Train. 2006;41(4):415-421.

42. Standards and Guidelines for Post-Certification Graduate Athletic Training Education Programs. Available at: http://nataec.org/AcademicPrograms/PostProfessionalEducation/ tabid/97/Default.aspx.. Accessed November 27, 2007.

43. Why certified students should enroll in an accredited graduate program. Available at: http://nataec.org/LinkClick.aspx?fileticket=O7oZ\%2b0NB5Do\%3d\&tabid=97\& mid=503. Accessed July 10, 2007. 
44. Issues and outcomes in graduate education. Available at: http://nataec.org/LinkClick.aspx?fileticket=JlxSzxF2Kag\%3d\&tabid=97\&mid=50 3. Accessed July 10, 2007.

45. Tang F, Chou S, Chiang H. Students' perceptions of effective and ineffective clinical instructors. J Nurs Ed. 2005;40(4):187-192.

46. Cangelosi PR. Accelerated second-degree baccalaureate nursing programs: what is the significance of clinical instructors? J Nurs Edu. 2007;46(9):400-405.

47. Neill KM, McCoy AK, Parry CB, Cohran J, Curtis JC, Ransom RB. The clinical experience of novice students in nursing. Nurse Educ. 1998;23(4):16-21.

48. Orland-Barak L, Wilhelem D. Novices in clinical practice settings: student nurses stories of learning the practice of nursing. Nurs Edu Today. 2005;25:455-464.

49. Botti M, Reeve R. Role of knowledge and ability in student nurses'clinical decision making. Nurs and Health Sciences. 2003;5:39-49.

50. West Virginia University Athletic Training Curriculum Clinical Education: Approved Clinical Instructor Retraining Workshop. 2007-2008 Academic year. 